\title{
Docosahexaenoic Acid Lessens Hepatic Lipid Accumulation and Inflammation via the AMP- Activated Protein Kinase and Endoplasmic Reticulum Stress Signaling Pathway in Grass Carp (Ctenopharyngodon Idella)
}

\section{Xiaocheng Huang}

Northwest Agriculture and Forestry University College of Animal Science and Technology

Jian Sun

Northwest Agriculture and Forestry University College of Animal Science and Technology

Chenchen Bian

Northwest Agriculture and Forestry University College of Animal Science and Technology

Shanghong Ji

Northwest Agriculture and Forestry University College of Animal Science and Technology

Hong ji ( $\square$ jihong@nwsuaf.edu.cn )

Northwest Agriculture and Forestry University

Short report

Keywords: AMPK, ER stress, DHA, Hepatic steatosis, Inflammation, Ctenopharyngodon idella

Posted Date: September 14th, 2021

DOl: https://doi.org/10.21203/rs.3.rs-845760/v1

License: (c) (1) This work is licensed under a Creative Commons Attribution 4.0 International License.

Read Full License

Version of Record: A version of this preprint was published at Food \& Function on January 1st, 2022. See the published version at https://doi.org/10.1039/D1F003214C. 


\section{Abstract}

Background: The liver is the primary organ for frontline immune defense and lipid metabolism. Excessive lipid accumulation in the liver severely affects its metabolic homeostasis and causes metabolic diseases. Docosahexaenoic acid (DHA) is known for its beneficial effects on lipid metabolism and antiinflammation, but its molecular mechanism remains unknown, especially in fish. In this study, we evaluated the protective effects of DHA on hepatic steatosis of grass carp (Ctenopharyngodon idella) in vivo and in vitro and mainly focused on lipogenesis and inflammation. Grass carp were fed with purified diets supplemented with $0 \%, 0.5 \%$ and $1 \%$ DHA for 8 weeks in vivo. Hepatocytes were treated with palmitic acid (PA) $(200 \mu \mathrm{M})$ with or without DHA (50 or $100 \mu \mathrm{M})$ for $24 \mathrm{~h}$ in vitro. In addition, Compound C (CC, the inhibitor of AMP-activated protein kinase) was used to examine the mechanism of DHA on hepatic steatosis in vitro.

Results: In this study, 1\% DHA significantly decreased the liver triglyceride (TG), malondialdehyde (MDA), serum tumor necrosis factor a (TNFa) and nuclear factor kappa B (NFKB) contents. DHA (100 $\mu \mathrm{M})$ effectively attenuated PA-induced lipid accumulation $(P<0.05)$. Furthermore, DHA significantly inhibited endoplasmic reticulum (ER) stress and stimulated the expression of AMP-activated protein kinase $(A M P K)$ and its downstream factors related to hepatic inflammation and lipogenesis in vivo and in vitro. However, the effects of DHA could be abrogated by CC in vitro.

Conclusions: DHA exerted a protective effect on hepatic steatosis by inhibiting ER stress, improving antioxidant ability, relieving hepatic inflammation and inhibiting hepatic lipogenesis in an AMPKdependent manner. Our findings give a theoretical foundation for further elucidation of the beneficial role of DHA in vertebrates.

\section{Background}

Aquatic products are known as high-protein and low-fat food, which are popular among different people worldwide. Therefore, the production of aquatic products develops the aquaculture industry and provides economic benefits. A high-energy diet is frequently used in aquaculture to increase growth speed and shortens the fish production cycle. Prolonged energy imbalance is associated with ectopic fat deposition, mainly in the liver and viscera [1, 2]. It promotes the prevalence of metabolic syndrome diseases (e.g., hepatic steatosis and liver inflammation) in aquatic animals $[3,4]$. Thus, it is important to explore mechanisms exerting liver protection in the aquaculture industry.

Hepatic steatosis is one of the most common chronic liver diseases in humans, which is mainly induced by high-energy diets [5]. Fatty liver can cause hepatitis, fibrosis and irreversible end-stage liver diseases, such as liver cirrhosis and cancer [6]. Fat overload is the critical predisposing factor for hepatic steatosis $[7,8]$. Different studies have focused on lipid accumulation in response to other nutrients and key molecules causing hepatic steatosis [9-11]. Docosahexaenoic acid (DHA, 22:6n-3) and eicosapentaenoic acid (EPA; 20:5n-3) are known as n-3 highly unsaturated fatty acids (HUFAs). HUFAs promote various 
critical physiological roles, such as growth performance improvement, cell membrane fluidity control, lipid metabolism regulation and immune function improvement in fish [12-14]. Studies have outlined numerous positive biological DHA impacts, such as anti-fibrogenic, anti-inflammatory and anti-obesity effects on liver protection $[15,16]$. Compared with the other $n-3$ fatty acids in the liver, DHA shows potent anti-fibrogenic effects by interfering with pro-inflammation transforming growth factor- $\beta$ (TGF $\beta$ ) and nuclear factor kappa-B (NF-kB) (signaling pathways [15]. However, DHA shows anti-inflammatory effects in several ways under different conditions. These include up-regulation of peroxisome proliferatoractivated nuclear receptor- $Y$ (PPARY), prevention of macrophage infiltration, activation of NF-KB and Jun $\mathrm{N}$-terminal Kinase (JNK) signaling pathways, suppression of leukocyte chemotaxis and blocking of proinflammatory cytokine and eicosanoid production [17-19]. Furthermore, data from mice fed a high-fat diet showed that DHA could down-regulate G Protein-Coupled Receptor 120 (GPR120) and stimulate the browning of white adipose tissue $[17,20,21]$. Although there are some potentially beneficial biological effects of DHA, the molecular mechanism by which DHA exerts its nutritional effects in the liver was not detected in fish.

DHA ameliorates the endoplasmic reticulum (ER) stress and lipid accumulation in hepatocytes. Hepatocytes contain numerous ER, which play an essential role in hepatocyte homeostasis [22]. ER stress is one of the critical factors in the pathogenic mechanism of lipid-related metabolic diseases (e.g., hepatic steatosis) [23]. ER stress is characterized by the up-regulated expression of marker genes [C/EBP homologous protein (CHOP), glucose-regulated protein 78 (GRP78) and phosphorylated protein kinaselike ER kinase (p-PERK)] [24]. ER stress evokes hepatic steatosis through increasing lipogenesis or decreasing lipoprotein secretion [23]. Therefore, relieving ER stress may be a useful method for the therapy of hepatic steatosis.

Grass carp (Ctenopharyngodon idella) is the most abundant freshwater aquaculture fish in China. It deposits excess fat in adipose tissue and liver during farming. So, it is considered a valuable model for studying hepatic steatosis [25]. Previously, our studies observed that moderate dietary intake of n-3 HUFAs is beneficial to improve growth performance and physiological conditions of grass carp and alleviates hepatopancreatic lipid accumulation $[14,26]$. We assumed that the protective effects of DHA on the liver could be associated with its ability to inhibit lipid accumulation. However, the exact molecular mechanism in fish remained obscure. Thus, this study aimed at investigating the underlying molecular mechanism of DHA that protects the liver.

\section{Materials And Methods}

Two experiments were performed in vivo and in vitro. All procedures were approved by the Northwest A\&F University Institutional Animal Care and Use Committee.

\subsection{Experiment 1: in vivo study}

\subsubsection{Experimental diets}


Three isonitrogenous and isoenergetic purified diets were formulated by adding different concentrations of DHA (Net content of 50\% $\triangle$ Xunda Marine Biological Products Co., Ltd., Jiangsu, China). The fish were divided into three groups based on the concentrations of DHA, including Control ( $0 \% \mathrm{DHA})$, and $0.5 \%$ and $1 \%$ DHA groups. The formulation and proximate composition of the experimental diets are demonstrated in Table 1. Soybean oil (Kerry Oils \& Grains Co., Shenzhen, China) and linseed oil (Hoval Seasons Bio-Sci Co., Changchun, China) were added to supplement $1 \%$ linoleic acid (LA) and $1 \%$ alpha-linolenic acid (LNA) essential fatty acid requirements, respectively. The experimental diets were prepared according to previously described methods [10].

\subsubsection{Experimental procedure}

Fish culture and management procedures used in this study were described by Shi et al. [25]. A total of 108 juvenile grass carp (initial weight: $29.76 \pm 2.34 \mathrm{~g}$ ) were distributed into 9 tanks (225-L) with 12 fish per tank. Diets were randomly assigned to three replicate tanks, and the feeding experiment lasted for 8 weeks.

At the end of the experiment, the fish were euthanized via immersion in tricaine methanesulfonate (MS222; $100 \mathrm{mg} / \mathrm{L}$ ) (Sigma, St. Louis, MO, USA). The final body weight (FBW, g), body length (BL, $\mathrm{cm}$ ), relative intestine length (RIL, \%), hepatosomatic index $(\mathrm{HSI}, \%)$, condition factor $\left(\mathrm{CF}, \mathrm{g} / \mathrm{cm}^{3}\right)$, survival rate $(\mathrm{SR}, \%)$, viscerosomatic index (VSI, \%), kidney index (KI, \%) and spleen index (SI, \%) of each fish were determined. Subsequently, triglyceride (TG) content, hematoxylin \& eosin (H\&E) staining, fatty acid composition, antioxidant enzymatic activities and relative gene expression levels of lipid synthesis, inflammation and ER stress were analyzed in the liver tissues.

An automatic biochemical analyzer (Hitachi 7180, Tokyo, Japan) was used to examine the serum biochemical indices, including alanine aminotransferase (ALT, $\mathrm{U} / \mathrm{mL}$ ), aspartate aminotransferase (AST, $\mathrm{U} / \mathrm{mL}$ ), total protein $(T P, g / L)$, albumin (ALB, $g / L)$, globulin (GLB, $g / L)$, albumin and globulin $(A / G)$ ratio, high-density lipoprotein cholesterol (HDL-C, mmol/L) and low-density lipoprotein cholesterol (LDL-C, $\mathrm{mmol} / \mathrm{L})$.

\subsection{Experiment 2: in vitro study}

\subsubsection{Cell culture and treatment}

We cultured the grass carp hepatocyte L8824 cell line as described previously [27]. The palmitic acid (PA; article no.: P5585) and DHA (article no.: D2534) were obtained from Sigma Aldrich (St. Louis, Missouri, USA). PA and DHA were dissolved in ethanol (Zhiyuan Chemical Reagent Co., Ltd., Tianjin, China) to prepare $100 \mathrm{mM}$ stock solution and then diluted with a medium containing $2 \%$ free fatty acid (FFA)-free bovine serum albumin (BSA) to obtain the designed concentrations before use. PA (200 $\mu \mathrm{M})$ with or without DHA (50 or $100 \mu \mathrm{M}$ ) was used to treat hepatocytes for $24 \mathrm{~h}$. We added $10 \mu \mathrm{M}$ Compound C (CC; an AMPK inhibitor, HY-13418; Medchem Express Inc., Monmouth Junction, NJ, USA) in water, and the AMPK inhibitor was added $2 \mathrm{~h}$ before fatty acid treatment. Briefly, the experiment was divided into four 
experimental groups: Control, $200 \mu \mathrm{M}$ PA, $200 \mu \mathrm{M}$ PA +DHA (50 or $100 \mu \mathrm{M})$ and $200 \mu \mathrm{M}$ PA $+100 \mu \mathrm{M}$ $\mathrm{DHA}+10 \mu \mathrm{M}$ CC (pretreatment for $2 \mathrm{~h}$ ).

\subsection{Sample analysis}

\subsubsection{Fatty acid composition analysis in experimental diets and liver samples}

We used gas chromatography (GC) to detect fatty acid composition as described previously [25]. The fatty acid composition of the experimental diets is observed in Table 3.

2.3.2. TG content, malondialdehyde (MDA) content and enzymatic activity assays on the liver and hepatocytes

The TG content was measured using a tissue triglyceride assay kit (Applygen Technologies Inc., Beijing, China). Then, antioxidant enzymatic activities, such as superoxide dismutase (SOD) and catalase (CAT), were measured [25]. The end products of lipid peroxidation MDA were measured using assay kits (Jian Cheng Biochemical Co. Nanjing, China).

\subsubsection{Liver histological processing and morphological evaluation, cell viability assays and Nile red staining}

We prepared liver sample sections and stained them with H\&E, as described previously [28]. These histological samples were observed and photographed under upright microscopy (Leica Biosystems, Germany), and relative cell viability was determined following standard instructions of the Cell Counting Kit-8 (K009-100T, Zeta Life Inc., USA) [29]. Briefly, hepatocytes were plated in a 96-well plate $\left(1 \times 10^{4}\right.$ cells/well) and cultured until these reached $85-90 \%$ confluence. Then, hepatocytes were treated with different concentrations of PA (100 or $200 \mu \mathrm{M})$, DHA $(50$ or $100 \mu \mathrm{M})$ and $200 \mu \mathrm{M}$ PA +100 $\mu \mathrm{M}$ DHA for 24 h. Then, we added $10 \mu \mathrm{l} \mathrm{CCK-8} \mathrm{solution} \mathrm{to} \mathrm{each} \mathrm{well} \mathrm{(total} \mathrm{reaction} \mathrm{volume} \mathrm{of} 110 \mu \mathrm{L}$ ) and incubated for another $3 \mathrm{~h}$. The absorbance was detected at the wavelength of $450 \mathrm{~nm}$. For observing the effect on lipid deposition, Nile red staining was used to view the lipid droplets in hepatocytes [30].

\subsubsection{Investigation of the concentrations of pro-inflammatory cytokines in serum by ELISA assay}

Pro-inflammatory cytokine concentrations, including TNFa and NFKB, were examined using Fish ELISA Assay kits (FANKEL Industrial Co., Ltd, Shanghai, China).

\subsubsection{Transcriptomic analysis of the liver samples}

We detected the transcriptome of DHA-fed grass carp liver as described by Jing et al. [31]. Briefly, total liver RNA ( 2 fish/tank) was extracted, and its concentration, purity and integrity were determined. Subsequently, the total RNA from fish in each tank was mixed in equivalent amounts (3 replicates per treatment). RNA was enriched, fragmented and reverse transcribed into complementary DNA (cDNA), and the second cDNA strand was synthesized. Consequently, the cDNA fragments were purified using 
magnetic bead precipitation and terminally repaired. poly (A) was added and attached to Illumina sequencing adapters. Finally, ligation products were size-selected through agarose gel electrophoresis, amplified using polymerase chain reaction (PCR) and sequenced using the Illumina novaseq 6000 platform (Sangon Biotech (Shanghai) Co., Ltd., China) following the manufacturer instructions.

\subsubsection{Quantitative real-time PCR (qPCR) and western blot analysis using liver samples and hepatocytes}

We investigated gene transcription levels based on our previous study [10]. The various primers used in this study are given in Table 2 . The comparative $\mathrm{Ct}$ method $\left(2^{-\Delta \Delta \mathrm{ct}}\right)$ was used to calculate the target gene expression values [32]. We obtained protein translation levels from our previous study [10]. The primary antibodies against FAS (WL03376, 1:1000, Wanleibio) and $\beta$-Actin (3779, 1:1000, Prosci) were applied. Finally, the secondary antibody, goat anti-rabbit horseradish peroxidase conjugate (A02010, 1:2000, Abbkine), was added.

\subsection{Statistical analysis}

All statistical analyses were performed with SPSS 25.0 software (SPSS, Chicago, IL, USA). Percentage data, such as the fatty acid composition of the liver, were arcsine-transformed before analysis [33]. The Shapiro-Wilk test was done to analyze the normality of the data distribution, and Levene's test was performed to examine the homogeneity of the variances. The differences among the treatments were analyzed by one-way analysis of variance (ANOVA) and compared by Duncan's test. The student's $t$ test was used for 2-group comparisons in vivo and in vitro. All data were then expressed as mean \pm standard deviation (SD), and $P<0.05$ was considered significant.

\section{Results}

\section{Experiment 1: In vivo study}

\subsection{Growth performance and biological indices}

In the 1\% DHA group, FBW was higher than that in the other two groups (Table 4, $P \square 0.05$ ). Also, compared with the control and $0.5 \%$ DHA groups, it effectively increased BL and decreased RIL and VSI, respectively (Table 4, $P \square$ 0.05). However, no significant differences in $\mathrm{CF}, \mathrm{SR}, \mathrm{KI}$ and SI were observed among the three treatments (Table 4). Serum ALT, ALB, HDL-c and LDL-c levels were altered in the $1 \%$ DHA group than those in the control group (Table 5, P<0.05). As illustrated in Table 5, AST, TP, GLO and A/G showed no significant differences among the three treatments.

\subsection{Fatty acid composition of liver}

In the liver samples, the DHA proportion was increased in fish-fed DHA in a dose-dependent manner compared with the control group (Table 6, $P \square$ 0.05). Besides, the n-3HUFA, n-3PUFA, PUFA and n-3PUFA/n6PUFA proportions were significantly increased in the 1\% DHA group (Table 6, $P \square 0.05$ ), whereas SFA was significantly decreased (Table 6, P $\square 0.05$ ). 


\subsection{DHA attenuates lipid accumulation and improves the antioxidant capacity of the liver}

We evaluated the effects of DHA on hepatic steatosis in vivo. Compared with the control group, histopathological examination based on H\&E staining showed that the DHA-fed fish effectively reduced lipid vacuoles and significantly increased the HSI value (Figs. $1 A$ and $B, P \square 0.05$ except $0.5 \%$ DHA group). Liver TG contents were significantly reduced in the 1\% DHA group compared with the control group (Fig. 1C, $P \square 0.05)$.

In the 1\% DHA group, MDA contents were significantly reduced than those in the control group (Fig. 1D, $P$ $\square$ 0.05). Although there were no significant differences in the SOD and CAT enzyme activities between the control and DHA groups, and there was an upward trend (Fig. 1E). Furthermore, the SOD and CAT mRNA assays confirmed the enzymatic activity assay results (Fig. 1F, $P \square 0.05$ ).

\subsection{DHA inhibits liver inflammation and hepatic lipid synthesis}

NFKB and TNFa serum levels were detected to clarify whether DHA had protective effects against inflammation in vivo. These parameters were significantly reduced in the $1 \%$ DHA group than those in the control group (Figs. $2 A$ and $B, P \square 0.05$ ). Additionally, this group showed a reduced expression in genes, including $T N F a, N F K B, I L-1 \beta, I L-6$ and $I L-8$, during liver inflammation compared with the control group (Figs. 2C and D, $P \square 0.05$ ).

We assessed whether DHA would attenuate lipogenesis-related gene expression in the liver. SREBP1C, $C / E B P 1 a, F A S$ and SCD1 mRNA expression levels were significantly reduced after adding 1\% DHA (Figs. $2 \mathrm{E}$ and $\mathrm{F}, P \square 0.05)$.

\subsection{DHA activates AMPK and inhibits ER stress signaling pathways}

In order to determine the underlying mechanism of DHA inhibiting hepatic steatosis and improving liver inflammation in grass carp, a functional enrichment analysis was done on the transcriptome data. The analysis showed that the lipid uptake (LDL-receptor) and metabolism and AMPK signaling pathways were up-regulated in the $1 \%$ DHA group compared with the control group (Figs. 3A and B).

Subsequently, we examined the AMPK expression in the mRNA level, which was increased nearly 1.5 -fold in the 1\% DHA group than the control group (Fig. 3C, $P \square$ 0.05). During ER stress, the mRNA expression levels of related genes, including CHOP, GRP78, IRE1, ATF6 and PERK, were significantly decreased in the 1\% DHA group (Figs. 3D and E, $P \square 0.05$ ).

\section{Experiment 2: In vitro study}

\subsection{PA-induced cell injury}

In palmitate-treated cells, cytotoxicity occurred in a dose-dependent manner, and their cell viability was decreased by half when treated with PA $(200 \mu \mathrm{M})$ (Figs. 4A and E, P[ 0.05). Besides, PA ( $200 \mu \mathrm{M})$ 
significantly increased the hepatocyte TG contents and up-regulated the hepatic lipid synthesis and liver inflammation-related-gene expression (Fig. 4B-D, $P \square 0.05$ ).

We performed CCK8 analyses [29] to assess the cytotoxic effects of DHA, and determined the optimal concentration for hepatocyte experiments. Besides, $50 \mu \mathrm{M}$ or $100 \mu \mathrm{M}$ DHA did not display any toxicity in the cells, and co-treatment with $100 \mu \mathrm{M}$ DHA prevented cytotoxic effects of PA (Fig. 4E, $P \square 0.05$ ). Finally, cell viability indicated that the DHA supplementation significantly enhanced cellular cytotoxicity (Fig. $4 \mathrm{E}, P \square 0.05)$.

\subsection{DHA ameliorates PA-induced inflammation and lipid synthesis in hepatocytes}

This study detected the TG contents and Nile red staining results to confirm whether DHA had a protective effect against palmitate-induced cell injury in grass carp hepatocytes. As illustrated in Fig. 5A, the intracellular neutral lipid Nile red staining demonstrated that DHA effectively alleviated PA-induced cellular damage. In the PA group, TG cell contents were increased than those in the control group, whereas DHA treatment significantly reduced PA-induced TG accumulation (Fig. 5B, $P \square 0.05$ ). We examined whether DHA decreased the related gene expression during hepatic lipid synthesis and hepatocyte inflammation in vitro. DHA treatment significantly reduced the expression of the corresponding genes, including FAS, SREBP1C, SCD1, C/EBPa, TNFa, IL-6, NFKB and IL-1 $\beta$ (Figs. 5C and D, $P \square$ 0.05). Furthermore, in the PA group, the FAS expression levels were increased than those in the control group. In contrast, DHA supplementation restrained this trend (Fig. 5E).

\subsection{DHA activates AMPK and inhibits ER stress signaling pathway to influence hepatic lipid synthesis and inflammation}

In vivo, DHA supplementation activated AMPK signaling pathway and inhibited ER stress signaling pathways (Fig. 3). We observed the mRNA expression of these pathways in vitro. Compared with the control group, the $A M P K$ expression was significantly decreased. However, the ER stress-related genes, including GRP78, CHOP, ATF6 and IRE1, were significantly increased in PA-induced hepatocyte steatosis. DHA application effectively ameliorated this trend (Figs. 6A and B, $P \square 0.05$ ). Compared with the PA group, the $100 \mu \mathrm{M}$ DHA supplementation reduced lipid accumulation. Nevertheless, these DHA effects could be confined using CC (Fig. 6C, $P \square$ 0.05). After DHA treatment, similar constraints of CC were also observed on the inflammation, hepatic lipogenesis and ER stress-related gene levels, including $N F K B, T N F a, I L-1 B, I L-6$, $S C D 1, C / E B P a$ and $C H O P$ (Fig. 6D, $P \square 0.05$ ).

\section{Discussion}

The liver is the primary organ that controls lipid homeostasis through complex signaling, biochemical and cellular pathways [34]. However, excess lipid accumulation in hepatic cells affects its functions and evokes diseases, including hepatic steatosis, inflammation, cell death and fibrosis $[35,36]$. However, it is important to explore the underlying cellular and molecular mechanisms influencing hepatic lipid metabolism. 
DHA is an n-3HUFA, which represents the most abundant fish oil component and exhibits various biological activities, such as anti-inflammatory, antioxidant and anti-obesity effects [27, 37, 38]. Previous studies mainly focused on the impact of DHA on mammalian cells $[15,16]$. To date, the detailed cellular and molecular mechanisms by which DHA affects lipid metabolism in teleosts remain obscure. Therefore, this study identified a positive DHA effect against hepatic steatosis in the grass carp by improving antioxidant ability, alleviating inflammation and suppressing hepatic lipid synthesis via activating and inhibiting the AMPK and ER stress signaling pathways (Fig. 7).

Serum ALT and AST are the major markers of liver function [39]. There are tissue injuries that cause many transaminases to enter the bloodstream, and they remain relatively stable and low [40,41]. The serum levels of ALT were reduced significantly in the 1\% DHA group in this study. In addition, lower serum LDL-C and HDL-c contents were also observed in the 1\% DHA group. In a previous study, serum LDL-C and HDL-C were reduced in C57BL/ $6 \mathrm{~J}$ mice, indicating that liver injury was lessened [42].

Under normal circumstances, the liver processes a mass of FA. Less than 5\% of FA is stored in a stable state as TG, and the relatively small amounts of TG stored in the liver are in the form of cytoplasmic lipid droplets (LDs) [34]. The hepatocytes accumulate excess TG contributing to steatosis and balloon cell degeneration, and it is considered a major evoking factor of fatty liver diseases [43, 44]. C/EBPa is a transcription factor that plays a critical regulatory role in lipogenesis. It is an effective therapeutic target for hepatocyte damage [45]. In addition, C/EBP $\beta$ promotes the transcription of SREBP-1c in the liver and adipocytes [46]. SREBP-1c is the primary transcription factor related to hepatic lipogenesis. It regulates the downstream transcription factors, including the genes encoding rate-limiting enzymes (e.g., FAS and SCD1) $[6,47]$. In obese mice induced by diet, it exerted anti-hepatic steatosis effects when the activity of SREBP-1c was inhibited [7]. Similarly, liver-specific SREBP-1c knockout mice indicated that the expression levels of lipogenic-related enzymes, including ACC1, FASN and SCD1, were significantly reduced, and the hepatic lipid content and TG plasma levels were lower than those of wild-type [48]. This study illustrated that the SREBP1c expression controlled several downstream-signaling components, including FAS and $S D 1$, consistent with other studies $[6,7,47,48]$. Besides, the above components were significantly upregulated in PA-induction, which subsequently increased the TG content. However, DHA treatment could converse these aberrant trends. Furthermore, in vivo studies confirmed that DHA lowered the hepatosomatic index, lipid vacuoles during the H\&E staining of liver samples, TG content and the expression of transcription factors related to hepatic lipogenesis in the liver. These results suggested that DHA could suppress hepatic lipogenesis and prevent PA-induced lipotoxicity in the liver.

Studies reported that FAS could induce hepatocyte inflammation, which is highly associated with lipid accumulation in the liver. The fatty liver cell model was established using PA, OA, or a mixture of fatty acids (OA: PA) [6, 29, 49]. Previously, DHA could alleviate OA-induced hepatocyte inflammation in grass carp, thus inhibiting the expression levels of transcription factors, such as $I L-8, T N F a$ and $N F K B$ [27]. PA is more toxic than other saturated or unsaturated fatty acids [50]. Our study determined whether DHA exerted anti-inflammatory effects in grass carp hepatocytes induced by PA. In our study, PA-induced hepatocyte injury caused hepatocyte lipoapoptosis by increasing the TG cell content and up-regulating 
the expression of related genes, such as $T N F a, I L-6, N F K B$ and $I L-1 \beta$, during hepatic inflammation. However, DHA supplementation reversed this trend. We also observed that DHA reduced the TNFa and NFKB serum contents and the expression of transcription factors related to liver inflammation in vivo. These results suggest that DHA exerts anti-inflammatory effects. Notably, specialized pro-resolving lipid mediators derived from DHA or EPA, such as resolvins, protectins and maresins, exert potent antiinflammatory effects in adipocytes [51,52]. Thus, this research area needs further exploration.

Generally, hepatic lipid accumulation is connected with ER stress, resulting in the progression of liver injury $[53,54]$. When the lipid levels in the liver vary significantly, the ER initiates multiple defense systems, termed as unfolded protein response (UPR), to maintain intracellular homeostasis [55]. ER stress can induce the synthesis of hepatic lipids via several mechanisms. It activates hepatic SREBP-1c, a transcription factor binding its membrane, which stimulates numerous hepatic lipogenesis pathways by activating enzyme encoding genes [56-58]. Similarly, in the intestinal epithelial cells of yellow catfish, the FA activated ER stress and induced TG accumulation. In contrast, pretreatment with 4-PBA, an inhibitor of ER stress, alleviated FA-induced accumulation of TG by reducing the expression levels of SREBP1c and $F A S$, which suggests that ER stress mediates FA-induced lipogenesis [33]. This study detected the in vivo and in vitro expression of ER stress-related genes, including CHOP, GRP78, IRE1, ATF6, and PERK. DHA inhibited hepatic lipogenesis by reducing the MRNA expression of SREBP1C and controlling several downstream-signaling components, including FAS and SD1. It also inhibited ER stress by decreasing the mRNA expression of GRP78, CHOP, ATF6 and IRE1. Based on these results, DHA relieves liver lipid accumulation by inhibiting ER stress and preventing liver injury.

This study used the transcriptomics approach to analyze the effects of DHA on the liver of grass carp and explore the mechanisms by which DHA protected against hepatic lipid synthesis and inflammation. We observed that lipid uptake, biological metabolism and AMPK signaling pathways were up-regulated in the $1 \%$ DHA group compared with the control group. AMPK is a heterotrimer containing three subunits, a catalytic $\alpha$-subunit and two regulatory subunits ( $\beta$ and $\gamma$ ). AMPK plays an essential role in controlling lipid metabolism, ameliorating hepatic inflammation and improving lipid peroxidation $[6,48,59]$. Our study hypothesized that AMPK could mediate the mechanisms by which DHA inhibited liver lipid synthesis and alleviated liver inflammation. We confirmed that DHA treatment increased the mRNA expression of AMPK in vivo and in vitro. To verify the potential mechanisms of AMPK in lipid accumulation in the liver, hepatocytes were pre-treated with CC, an AMPK antagonist. We also used CC to evaluate the effects of DHA against hepatic lipid synthesis and inflammation. However, CC eliminated the effect of DHA in inhibiting ER stress signaling by up-regulating $C H O P$ mRNA expression, which is a crucial marker for ER stress. Consistent with a previous study on HFD-induced obesity in mice, the present study showed that AMPK inhibited lipid-induced ER stress and TG accumulation in liver hepatocytes [60, 61]. Taken together, these results demonstrate that DHA acts as an AMPK agonist to protect the liver from damage by inhibiting the ER stress signaling pathway. These processes subsequently relieve hepatic lipid synthesis and inflammation. 


\section{Conclusions}

This study identified a novel mechanism for regulating hepatic lipid metabolism in grass carp mediated via DHA treatment. It clarifies that DHA exerts a protective effect on hepatic steatosis by inhibiting ER stress, improving antioxidant ability, relieving hepatic inflammation and inhibiting hepatic lipogenesis in an AMPK-dependent manner. Moreover, our study has emphasized the importance of AMPK and ER stress signaling pathways in regulating hepatic lipid metabolism in grass carp.

\section{Abbreviations}

$\mathrm{A} / \mathrm{G}$, the ratio of albumin and globulin; ALT, alanine aminotransferase; $A M P K \otimes A M P$ activated protein kinase $\triangle A S T$, aspartate aminotransferase; $A T F 6$, activating transcription factor 6 ; $\mathrm{BL}$, body length; $C / E B P a$, CCAAT-enhancer-binding protein a; CAT, catalase; CC, Compound C; CF, condition factor; $\mathrm{CHOP}$, CCAAT/enhancer-binding protein homologous protein; DHAXDocosahexaenoic acid囚ER stress, Endoplasmic Reticulum stress; FAS, fatty acid synthase; FBW, final body weight; GLB, globulin; GLU, glucose; Gpr120, G Protein Coupled Receptor 120; GRP78, glucose-regulated protein 78; H\&E staining, hematoxylin-eosin staining; HDL-c, high-density lipoprotein cholesterol; HFD, high-fat diet; HSI, hepatosomatic index; IL-1 $\beta$, interleukin-1 $\beta$; IL-6, interleukin-6; IR, insulin resistance; IRE1, inositol-requiring enzyme; JNK, Jun N-terminal Kinase; KI, Kidney index; LA, linoleic acid; LDL-c, low-density lipoprotein cholesterol; LNA, linolenic acid; MDA, malondialdehyde; MUFA, monounsaturated fatty acid; n-3 HUFA, n-3 highly unsaturated fatty acids; n-3 PUFA, n-3 polyunsaturated fatty acids; n-3PUFA, n-3 polyunsaturated fatty acids; n-3PUFA/n-6PUFA, the ratio of $n-3$ polyunsaturated fatty acids and $n-6$ polyunsaturated fatty acids; $\mathrm{n}-6$ PUFA, n-6 polyunsaturated fatty acids; $N F K B$, nuclear factor kappa-B; OA, oleic acid; PA, palmitic acid; $P E R K$, protein kinase RNA-like ER kinase; PPARY, peroxisome proliferator-activated nuclear receptor- $ү$; RIL, relative intestine length; $S C D 1$, stearoyl-CoA desaturase 1; SFA, saturated fatty acids; SI, Spleen index; SOD, superoxide dismutase; SR, Survival rate; SREBP1C, sterol regulatory element-binding protein $1 \mathrm{c} ; \mathrm{TG}$, Triglyceride; TGF $\beta$, transforming growth factor- $\beta$; TNFa, tumor necrosis factor-a囚TP, total protein; ALB, albumin; UPR, unfolded protein response; VSI, Viscerosomatic index.

\section{Declarations}

\section{Ethics approval and consent to participate}

The experimental protocol of this study was approved by the Northwest A\&F University Institutional Animal Care and Use Committee.

\section{Consent for publication}

All authors read and approved the final manuscript, and consent for publication.

\section{Availability of data and material}


The data are shown in the main manuscript.

\section{Competing interests}

We declare that we have no financial and personal relationships with other people or organizations that can inappropriately influence our work, there is no professional or other personal interest of any nature or kind in any product, service and/or company that could be construed as influencing the content of this paper.

\section{Funding}

This work was financially supported by the National Nature Science Foundation of China (NSFC, Grant Number: 31772863) and China Postdoctoral Science Foundation Funded Project (2019M660266).

\section{Authors' contributions}

The authors' responsibilities were as follows-Ji Hong, Sun Jian and Huang Xiaocheng: contributed to the conception and design of the study; Huang Xiaocheng, Bian Chenchen and Ji Shanghong: conducted the experiment and sample analysis; Huang Xiaocheng, Ji Hong and Sun Jian: analyzed the data; Huang Xiaocheng: drafted the manuscript; Ji Hong, Sun Jian, Bian Chenchen and Ji Shanghong: revised the manuscript; All authors: contributed to interpreting the results, and read and approved the final manuscript.

\section{Acknowledgements}

Not applicable

\section{References}

1. Guo X, Liang XF, Fang L, Yuan X, Zhou Y, Zhang J, Li B. Effects of dietary non-protein energy source levels on growth performance, body composition and lipid metabolism in herbivorous grass carp (Ctenopharyngodon idella Val.) [J]. Aquaculture Research. 2015, 46:1197-1208. https://doi.org/10.1111/are.12275

2. Tian JJ, Lu RH, Ji H, et al. Comparative analysis of the hepatopancreas transcriptome of grass carp (Ctenopharyngodon idellus) fed with lard oil and fish oil diets. Gene. 2015;565(2):192-200. https://doi.org/10.1016/j.gene.2015.04.010

3. He AY, Ning LJ, Chen LQ, et al. Systemic adaptation of lipid metabolism in response to low- and highfat diet in Nile tilapia (Oreochromis niloticus). Physiol Rep. 2015;3(8):e12485. https://doi.org/10.14814/phy2.12485

4. Yan J, Liao K, Wang T, Mai K, Xu W, Ai Q. Dietary Lipid Levels Influence Lipid Deposition in the Liver of Large Yellow Croaker (Larimichthys crocea) by Regulating Lipoprotein Receptors, Fatty Acid 
Uptake and Triacylglycerol Synthesis and Catabolism at the Transcriptional Level. PLoS One. 2015;10(6):e0129937. https://doi.org/10.1371/journal.pone.0129937

5. Carr RM, Ahima RS. Pathophysiology of lipid droplet proteins in liver diseases. Exp Cell Res. 2016;340(2):187-192. https://doi.org/10.1016/j.yexcr.2015.10.021

6. Cha SH, Hwang Y, Heo SJ, Jun HS. Diphlorethohydroxycarmalol Attenuates Palmitate-Induced Hepatic Lipogenesis and Inflammation. Mar Drugs. 2020;18(9):475.

https://doi.org/10.3390/md18090475

7. Li Y, Xu S, Mihaylova MM, Zheng B, Hou X, Jiang B, Park O, Luo Z, Lefai E, Shyy JY, et al. AMPK phosphorylates and inhibits SREBP activity to attenuate hepatic steatosis and atherosclerosis in dietinduced insulin-resistant mice. Cell Metab. 2011;13(4):376-388.

https://doi.org/10.1016/j.cmet.2011.03.009

8. Monsénégo J, Mansouri A, Akkaoui M, et al. Enhancing liver mitochondrial fatty acid oxidation capacity in obese mice improves insulin sensitivity independently of hepatic steatosis. J Hepatol. 2012;56(3):632-639. https://doi.org/10.1016/j.jhep.2011.10.008

9. Liu P, Ji H, Li C, Tian J, Wang Y, Yu P. Ontogenetic development of adipose tissue in grass carp (Ctenopharyngodon idellus). Fish Physiol Biochem. 2015;41(4):867-878. https://doi.org/10.1007/s10695-015-0053-x

10. Jin A, Lei CX, Tian JJ, Sun J, Ji H. Dietary docosahexaenoic acid decreased lipid accumulation via inducing adipocytes apoptosis of grass carp, Ctenopharygodon idella. Fish Physiol Biochem. 2018;44(1):197-207. https://doi.org/10.1007/s10695-017-0424-6

11. Song YF, Hogstrand C, Ling SC, Chen GH, Luo Z. Creb-Pgc1a pathway modulates the interaction between lipid droplets and mitochondria and influences high fat diet-induced changes of lipid metabolism in the liver and isolated hepatocytes of yellow catfish. J Nutr Biochem. 2020;80:108364. https://doi.org/10.1016/j.jnutbio.2020.108364

12. Yu H, Gao Q, Dong S, Zhou J, Ye Z, Lan Y. Effects of dietary n-3 highly unsaturated fatty acids (HUFAs) on growth, fatty acid profiles, antioxidant capacity and immunity of sea cucumber Apostichopus japonicus (Selenka). Fish Shellfish Immunol. 2016;54:211-219. https://doi.org/10.1016/j.fsi.2016.04.013

13. Kiron V, Thawonsuwan J, Panigrahi A, et al. Antioxidant and immune defences of rainbow trout (Oncorhynchus mykiss) offered plant oils differing in fatty acid profiles from early stages[J]. Aquaculture Nutrition, 2015, 17(2):130-140. https://doi.org/10.1111/j.1365-2095.2009.00715.x

14. Ji H, Li J, Liu P. Regulation of growth performance and lipid metabolism by dietary n-3 highly unsaturated fatty acids in juvenile grass carp, Ctenopharyngodon idellus. Comp Biochem Physiol B Biochem Mol Biol. 2011;159(1):49-56. https://doi.org/10.1016/j.cbpb.2011.01.009

15. Enguita M, Razquin N, Pamplona R, Quiroga J, Prieto J, Fortes P. The cirrhotic liver is depleted of docosahexaenoic acid (DHA), a key modulator of NF-KB and TGF $\beta$ pathways in hepatic stellate cells. Cell Death Dis. 2019;10(1):14. https://doi.org/10.1038/s41419-018-1243-0 
16. Todorčević M, Hodson L. The Effect of Marine Derived n-3 Fatty Acids on Adipose Tissue Metabolism and Function. J Clin Med. 2015;5(1):3. https://doi.org/10.3390/jcm5010003

17. Wei $W$, Hu $M$, Huang $J$, et al. Anti-obesity effects of DHA and EPA in high fat-induced insulin resistant mice. Food Funct. 2021;12(4):1614-1625. https://doi.org/10.1039/d0fo02448a

18. Todoric J, Löffler M, Huber J, et al. Adipose tissue inflammation induced by high-fat diet in obese diabetic mice is prevented by n-3 polyunsaturated fatty acids. Diabetologia. 2006;49(9):2109-2119. https://doi.org/10.1007/s00125-006-0300-x

19. Rodríguez-Cruz M, Serna DS. Nutrigenomics of $\omega-3$ fatty acids: Regulators of the master transcription factors. Nutrition. 2017;41:90-96. https://doi.org/10.1016/j.nut.2017.04.012

20. Oh DY, Talukdar S, Bae EJ, et al. GPR120 is an omega-3 fatty acid receptor mediating potent antiinflammatory and insulin-sensitizing effects. Cell. 2010;142(5):687-698.

https://doi.org/10.1016/j.cell.2010.07.041

21. Zhuang P, Lu Y, Shou Q, et al. Differential Anti-Adipogenic Effects of Eicosapentaenoic and Docosahexaenoic Acids in Obesity. Mol Nutr Food Res. 2019;63(14):e1801135. https://doi.org/10.1002/mnfr.201801135

22. Wang $S$, Kaufman RJ. How does protein misfolding in the endoplasmic reticulum affect lipid metabolism in the liver?. Curr Opin Lipidol. 2014;25(2):125-132.

https://doi.org/10.1097/MOL.0000000000000056

23. Zhang $L$, Wang $\mathrm{HH}$. The essential functions of endoplasmic reticulum chaperones in hepatic lipid metabolism. Dig Liver Dis. 2016;48(7):709-716. https://doi.org/10.1016/j.dld.2016.03.016

24. Lebeaupin C, Vallée D, Hazari Y, Hetz C, Chevet E, Bailly-Maitre B. Endoplasmic reticulum stress signalling and the pathogenesis of non-alcoholic fatty liver disease. J Hepatol. 2018;69(4):927-947. https://doi.org/10.1016/j.jhep.2018.06.008

25. Shi XC, Jin A, Sun J, et al. a-lipoic acid ameliorates n-3 highly-unsaturated fatty acids induced lipid peroxidation via regulating antioxidant defenses in grass carp (Ctenopharyngodon idellus). Fish Shellfish Immunol. 2017;67:359-367. https://doi.org/10.1016/j.fsi.2017.06.036

26. Ji H, Cao Y Z, Liu P, et al. Effect of dietary HUFA on the lipid metabolism in grass carp Ctenopharyngodon idellus[J]. Acta Hydrobiologica Sinica, 2009, 33(5):881-889. https://doi.org/10.3724/SP.J.1035.2009.50881

27. Jin A, Shi XC, Deng W, Sun J, Ji H. Ameliorative effect of docosahexaenoic acid on hepatocyte apoptosis and inflammation induced by oleic acid in grass carp, Ctenopharyngodon idella. Fish Physiol Biochem. 2019;45(3):1091-1099. https://doi.org/10.1007/s10695-019-00623-8

28. Shi XC, Jin A, Sun J, et al. The protein-sparing effect of a-lipoic acid in juvenile grass carp, Ctenopharyngodon idellus: effects on lipolysis, fatty acid $\beta$-oxidation and protein synthesis. $\mathrm{Br} \mathrm{J}$ Nutr. 2018;120(9):977-987. https://doi.org/10.1017/S000711451800226X

29. Xu N, Luo H, Li M, et al. $\beta$-patchoulene improves lipid metabolism to alleviate non-alcoholic fatty liver disease via activating AMPK signaling pathway. Biomed Pharmacother. 2021;134:111104. https://doi.org/10.1016/j.biopha.2020.111104 


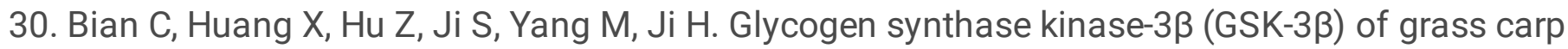
(Ctenopharyngodon idella): Synteny, structure, tissue distribution and expression in oleic acid (OA)induced adipocytes and hepatocytes. Comp Biochem Physiol B Biochem Mol Biol. 2020;241:110391. https://doi.org/10.1016/j.cbpb.2019.110391

31. Tian JJ, Lei CX, Ji H, et al. Dietary arachidonic acid decreases the expression of transcripts related to adipocyte development and chronic inflammation in the adipose tissue of juvenile grass carp, Ctenopharyngodon idella. Comp Biochem Physiol Part D Genomics Proteomics. 2019;30:122-132. https://doi.org/10.1016/j.cbd.2019.02.006

32. Pfaffl MW. A new mathematical model for relative quantification in real-time RT-PCR. Nucleic Acids Res. 2001;29(9):e45. https://doi.org/10.1093/nar/29.9.e45

33. Ling SC, Wu K, Zhang DG, Luo Z. Endoplasmic Reticulum Stress-Mediated Autophagy and Apoptosis Alleviate Dietary Fat-Induced Triglyceride Accumulation in the Intestine and in Isolated Intestinal Epithelial Cells of Yellow Catfish. J Nutr. 2019;149(10):1732-1741. https://doi.org/10.1093/jn/nxz135

34. Alves-Bezerra M, Cohen DE. Triglyceride Metabolism in the Liver. Compr Physiol. 2017;8(1):1-8. https://doi.org/10.1002/cphy.c170012

35. Liao CC, Ou TT, Huang HP, Wang CJ. The inhibition of oleic acid induced hepatic lipogenesis and the promotion of lipolysis by caffeic acid via up-regulation of AMP-activated kinase. J Sci Food Agric. 2014;94(6):1154-1162. https://doi.org/10.1002/jsfa.6386

36. Ahmed A, Wong RJ, Harrison SA. Nonalcoholic Fatty Liver Disease Review: Diagnosis, Treatment, and Outcomes. Clin Gastroenterol Hepatol. 2015;13(12):2062-2070. https://doi.org/10.1016/j.cgh.2015.07.029

37. Martínez-Fernández L, Laiglesia LM, Huerta AE, Martínez JA, Moreno-Aliaga MJ. Omega-3 fatty acids and adipose tissue function in obesity and metabolic syndrome. Prostaglandins Other Lipid Mediat. 2015;121(Pt A):24-41. https://doi.org/10.1016/j.prostaglandins.2015.07.003

38. Prostek A, Gajewska M, Kamola D, Bałasińska B. The influence of EPA and DHA on markers of inflammation in 3T3-L1 cells at different stages of cellular maturation. Lipids Health Dis. 2014;13:3. https://doi.org/10.1186/1476-511X-13-3

39. Nazeri S, Farhangi M, Modarres S. The effect of different dietary inclusion levels of rutin (a flavonoid) on some liver enzyme activities and oxidative stress indices in rainbow trout, Oncorhynchus mykiss (Walbaum) exposed to Oxytetracycline. Aquaculture Research, 2017; 48 (8), 4356-4362. https://doi.org/10.1111/are.13257

40. M Martínez-Porchas, M Hernández-Rodríguez, HLE Gutierrez-Millán. Evaluation of the physiological status of the Pacific sardine, Sardinops sagax caeruleus, acclimated to different thermal regimes based on selected blood parameters. Environmental Biology of Fishes, 2011; 91 (1), 39-49. https://doi.org/10.1007/s10641-010-9757-z

41. Rudneva, Irina. Biomarkers for Stress in Fish Embryos and Larvae. CRC PRESS 2014; 1:43-48. 
42. Sheng D, Zhao S, Gao L, et al. BabaoDan attenuates high-fat diet-induced non-alcoholic fatty liver disease via activation of AMPK signaling. Cell Biosci. 2019;9:77. https://doi.org/10.1186/s13578019-0339-2

43. Donnelly KL, Smith $\mathrm{Cl}$, Schwarzenberg SJ, Jessurun J, Boldt MD, Parks EJ. Sources of fatty acids stored in liver and secreted via lipoproteins in patients with nonalcoholic fatty liver disease. J Clin Invest. 2005;115(5):1343-1351. https://doi.org/10.1172/JCl23621

44. Gómez-Lechón MJ, Donato MT, Martínez-Romero A, Jiménez N, Castell JV, O'Connor JE. A human hepatocellular in vitro model to investigate steatosis. Chem Biol Interact. 2007;165(2):106-116. https://doi.org/10.1016/j.cbi.2006.11.004

45. Tao LL, Ding D, Yin WH, et al. TSA increases C/EBP-a expression by increasing its lysine acetylation in hepatic stellate cells. Mol Med Rep. 2017;16(5):6088-6093. https://doi.org/10.3892/mmr.2017.7358

46. Tian J, Goldstein JL, Brown MS. Insulin induction of SREBP-1c in rodent liver requires LXRa-C/EBP $\beta$ complex. Proc Natl Acad Sci U S A. 2016;113(29):8182-8187.

https://doi.org/10.1073/pnas.1608987113

47. Fang $K$, Wu F, Chen $G$, et al. Diosgenin ameliorates palmitic acid-induced lipid accumulation via AMPK/ACC/CPT-1A and SREBP-1c/FAS signaling pathways in LO2 cells. BMC Complement Altern Med. 2019;19(1):255. https://doi.org/10.1186/s12906-019-2671-9

48. Liang G, Yang J, Horton JD, Hammer RE, Goldstein JL, Brown MS. Diminished hepatic response to fasting/refeeding and liver $X$ receptor agonists in mice with selective deficiency of sterol regulatory element-binding protein-1c. J Biol Chem. 2002;277(11):9520-9528.

https://doi.org/10.1074/jbc.M111421200

49. Kang OH, Kim SB, Seo YS, et al. Curcumin decreases oleic acid-induced lipid accumulation via AMPK phosphorylation in hepatocarcinoma cells. Eur Rev Med Pharmacol Sci. 2013;17(19):2578-2586.

50. Malhi H, Bronk SF, Werneburg NW, Gores GJ. Free fatty acids induce JNK-dependent hepatocyte lipoapoptosis. J Biol Chem. 2006;281(17):12093-12101. https://doi.org/10.1074/jbc.M510660200

51. Titos E, Rius B, González-Périz A, et al. Resolvin D1 and its precursor docosahexaenoic acid promote resolution of adipose tissue inflammation by eliciting macrophage polarization toward an M2-like phenotype. J Immunol. 2011;187(10):5408-5418. https://doi.org/10.4049/jimmunol.1100225

52. Laiglesia LM, Lorente-Cebrián S, López-Yoldi M, et al. Maresin 1 inhibits TNF-alpha-induced lipolysis and autophagy in 3T3-L1 adipocytes. J Cell Physiol. 2018;233(3):2238-2246. https://doi.org/10.1002/jcp.26096

53. Koo SH. Nonalcoholic fatty liver disease: molecular mechanisms for the hepatic steatosis. Clin Mol Hepatol. 2013;19(3):210-215. https://doi.org/10.3350/cmh.2013.19.3.210

54. Zhou H, Liu R. ER stress and hepatic lipid metabolism. Front Genet. 2014;5:112. https://doi.org/10.3389/fgene.2014.00112

55. Stevenson J, Huang EY, Olzmann JA. Endoplasmic Reticulum-Associated Degradation and Lipid Homeostasis. Annu Rev Nutr. 2016;36:511-542. https://doi.org/10.1146/annurev-nutr-071715- 
051030

56. Kammoun HL, Chabanon H, Hainault I, et al. GRP78 expression inhibits insulin and ER stress-induced SREBP-1c activation and reduces hepatic steatosis in mice. J Clin Invest. 2009;119(5):1201-1215. https://doi.org/10.1172/JCl37007

57. Horton JD. Sterol regulatory element-binding proteins: transcriptional activators of lipid synthesis. Biochem Soc Trans. 2002;30(Pt 6):1091-1095. https://doi.org/10.1042/bst0301091

58. Lee JS, Mendez R, Heng HH, Yang ZQ, Zhang K. Pharmacological ER stress promotes hepatic lipogenesis and lipid droplet formation. Am J Transl Res. 2012;4(1):102-113.

59. Ronnett GV, Kleman AM, Kim EK, Landree LE, Tu Y. Fatty acid metabolism, the central nervous system, and feeding. Obesity (Silver Spring). 2006;14 Suppl 5:201S-207S. https://doi.org/10.1038/oby.2006.309

60. Li H, Min Q, Ouyang C, et al. AMPK activation prevents excess nutrient-induced hepatic lipid accumulation by inhibiting $\mathrm{mTORC} 1$ signaling and endoplasmic reticulum stress response. Biochim Biophys Acta. 2014;1842(9):1844-1854. https://doi.org/10.1016/j.bbadis.2014.07.002

61. Kim JH, Sim HA, Jung DY, et al. Poria cocus Wolf Extract Ameliorates Hepatic Steatosis through Regulation of Lipid Metabolism, Inhibition of ER Stress, and Activation of Autophagy via AMPK Activation. Int J Mol Sci. 2019;20(19):4801. https://doi.org/10.3390/ijms20194801

\section{Tables}

Table1. Formulation and proximate composition of experimental diets. 


\begin{tabular}{lccc} 
Components & Group & & \\
& Control & $0.5 \% \mathrm{DHA}$ & $1 \% \mathrm{DHA}$ \\
\hline Ingredients (g/kg) & & & \\
\hline Casein & 320 & 320 & 320 \\
\hline Gelatin & 80 & 80 & 80 \\
\hline Dextrin & 280 & 280 & 280 \\
\hline Cellulose & 189 & 189 & 189 \\
\hline Soybean oil & 11 & 11 & 11 \\
\hline Linseed oil & 19 & 19 & 19 \\
\hline Lard oil & 30 & 20 & 10 \\
\hline DHA & 0 & 10 & 20 \\
\hline Carboxymethylcellulose & 20 & 20 & 20 \\
\hline Mineral mix ${ }^{1}$ & 40 & 40 & 40 \\
\hline Vitamin mix ${ }^{2}$ & 10 & 10 & 10 \\
\hline BHT & 1 & 1 & 1 \\
\hline Total & 1000 & 1000 & 1000 \\
\hline Chemical composition (percentage of dry matter basis) \\
\hline Crude fat (\%) & 5.42 & 5.66 & 5.60 \\
\hline Crude protein (\%, N\% $\times 6.25)$ & 36.48 & 36.12 & 36.0 \\
\hline Moisture (\%) & 9.80 & 9.98 & 9.56 \\
\hline Ash (\%) & 5.83 & 5.86 & 5.89 \\
\hline
\end{tabular}

1 The mineral mix contained $\left(\mathrm{g} / 100 \mathrm{~g}\right.$ of the total mineral) the following ingredients: $\mathrm{KAl}\left(\mathrm{SO}_{4}\right)_{2}, 0.159$; $\mathrm{CaCO}_{3}, 18.101, \mathrm{Ca}\left(\mathrm{H}_{2} \mathrm{PO}_{4}\right)_{2}, 44.601 ; \mathrm{CoCl}, 0.070 ; \mathrm{MgSO}_{4}, 5.216 ; \mathrm{MnSO}_{4} \cdot \mathrm{H}_{2} \mathrm{O}, 0.070 ; \mathrm{KCl}, 16.553 ; \mathrm{KI}, 0.014$; $\mathrm{ZnCO}_{3}, 0.192 ; \mathrm{NaH}_{2} \mathrm{PO}_{4}, 13.605 ; \mathrm{Na}_{2} \mathrm{SeO}_{3}, 0.006 ; \mathrm{CuSO}_{4} \cdot 5 \mathrm{H}_{2} \mathrm{O}, 0.075 ;$ Ferric citrate, 1.338.

2 The vitamin mix contained (mg/1000 g of diet) the following ingredients: vitamin C, 200; thiamine, 10; riboflavin, 20; vitamin A, 3000IU; vitamin E, 50IU; vitamin D3, 1500IU; menadione, 10; pyridoxine $\mathrm{HCl}, 10$; cyanocobalamin, 0.02; biotin,1.0; calcium pantothenate, 40; folic acid, 5; niacin, 20; inositol, 400; choline chloride, 2000; cellulose was used as a carrier. 
Table 2. Primers used in qPCR analysis.

\begin{tabular}{lll} 
gene & Forward (5'-3') & Reverse (5'-3') \\
\hline SREBP1C & TCACTCCAAATGGTGGTCGTCAGT & AAAGTGTTCAGACAGGCTTTGGGC \\
\hline FAS & CCTCAGCTTACAGCAGAATC & CTCTTCAGCAAGGGAGTTTAG \\
\hline C/EBPa & ACCCACATACCACCACTCTCAACA & TTTCCCTCGATCGCCCATCTTCAT \\
\hline SCD1 & GCCTTCCAGAATGACATCTAC & GCCGATGTGAGCAAAGAA \\
\hline NFKB & GAAGAAGGATGTGGGAGATG & TGTTGTCGTAGATGGGCTGAG \\
\hline TNFa & CGCTGCTGTCTGCTTCAC & CCTGGTCCTGGTTCACTC \\
\hline IL-6 & AGCCAGCTCCAGGTGAGTGAAG & GACGGCTCTGCATGTGTCGATC \\
\hline IL-1 $\beta$ & GCCAAGTAGCCGAATCACAGA & AAGCCCAAGATATGCAGGAGTC \\
\hline IL-8 & ATGAGTCTTAGAGGTCTGGGT & ACAGTGAGGGCTAGGAGGG \\
\hline ATF6 & AGCTGGAGGATCTTGGGGAT & TGATCGAGGGCTACTCCACA \\
\hline CHOP & GCGTGGTATGAAGACCTACAG & CGCTGACCATCGTTTCCA \\
\hline GRP78 & TTCAAGCCGGAGTTCTGTCC & GTTGTCAGAAGCGGTGGAGA \\
\hline IRE1 & CCTGCATGGTAGACATCTTCTC & TTCTCTGGCTCCATGCTTAAC \\
\hline PERK & AAGGTCATGCGAGAGGTAAAG & CATGAGAAGTCCACTGGAGAAG \\
\hline SOD & GGAGACCTTGGTAATGTGATAG & CATGGTCCTCCCAATGATG \\
\hline CAT & GACTAAGGTCTGGTCCCATAA & TGTTCAACCTCAGCGAAATAG \\
\hline AMPKa1 & TAGTGGCCGAGACTCAACCG & TCTGGCTACGGATTCCCAGG \\
\hline AMPKa2 & AGTTCTACCTGGCCTCCAGT & GAGAGCATCCAGAGGGCATC \\
\hline TCCACCTTCCAGCAGATGTGGATT & AGTTTGAGTCGGCGTGAAGTGGTA
\end{tabular}

Abbreviations: AMPKa1, AMP activated protein kinasea 1; AMPKa2, AMP activated protein kinasea 2; ATF6, activating transcription factor 6; C/EBPa, CAAT enhancer binding protein a; $C H O P$, CCAAT/enhancer-binding protein homologous protein; $F A S$, fatty acid synthase; GRP78, glucose-regulated protein 78; IL-1 $\beta$, interleukin-1 $\beta$; IL-6, interleukin-6; IL-8, interleukin-8; IRE1, inositol-requiring enzyme; $N F K B$, nuclear factor kappa-B; $P E R K$, protein kinase RNA-like ER kinase; $S C D 1$, stearoyl-CoA desaturase 1; $S O D$, superoxide dismutase; $C A T$, catalase; $S R E B P 1 C$, sterol regulatory element-binding protein-1c; $T N F a$, tumor necrosis factor-a.

Table 3. Fatty acid composition of the experimental diets (\% total fatty acids). 


\begin{tabular}{llll} 
Components & Group & & \\
\hline & Control & $0.5 \%$ DHA & $1 \%$ DHA \\
\hline $14: 0$ & 1.0 & 1.6 & 1.3 \\
\hline $16: 0$ & 18.2 & 15.3 & 12.0 \\
\hline $18: 0$ & 12.0 & 9.9 & 7.2 \\
\hline SFA & 31.1 & 26.7 & 20.5 \\
\hline 16:1n-7 & 1.3 & 1.2 & 0.8 \\
\hline 18:1n-9c & 30.3 & 27.1 & 21.6 \\
\hline MUFA & 31.6 & 28.3 & 22.3 \\
\hline 18:2n-6 & 19.3 & 18.7 & 18.6 \\
\hline 18:3n-6 & 0.5 & 0.5 & 0.8 \\
\hline $20: 4 n-6$ & 0.2 & 0.7 & 0.6 \\
\hline $22: 4 n-6$ & 0.2 & 0.7 & 1.5 \\
\hline n-6PUFA & 20.1 & 20.5 & 21.6 \\
\hline 18:3n-3 & 16.4 & 17.1 & 19.1 \\
\hline $20: 5 n-3$ & 0.1 & 1.2 & 2.6 \\
\hline $22: 6 n-3$ & 0.1 & 7.6 & 16.9 \\
\hline n-3HUFA & 0.2 & 8.7 & 19.4 \\
\hline n-3PUFA & 16.6 & 25.8 & 38.5 \\
\hline PUFA & 36.7 & 46.3 & 60.1 \\
\hline n-3/n-6PUFA & 0.8 & 1.3 & 1.8 \\
\hline
\end{tabular}

Abbreviations: MUFA, monounsaturated fatty acid; n-3 PUFA, n-3 polyunsaturated fatty acids; n-3PUFA, n3 polyunsaturated fatty acids; n-3PUFA/n-6PUFA, the ratio of $n-3$ polyunsaturated fatty acids and $n-6$ polyunsaturated fatty acids; n-6 PUFA, n-6 polyunsaturated fatty acids; SFA, saturated fatty acids.

Table 4. Effect of dietary DHA on growth performance and biological indices of grass carp ${ }^{1}$. 


\begin{tabular}{llll} 
Parameter & Group & & \\
& Control & $0.5 \% \mathrm{DHA}$ & $1 \% \mathrm{DHA}$ \\
\hline $\mathrm{IBW}(\mathrm{g})$ & $29.8 \pm 0.22$ & $29.8 \pm 0.01$ & $29.8 \pm 0.02$ \\
\hline $\mathrm{FBW}(\mathrm{g})$ & $39.4 \pm 1.55^{\mathrm{b}}$ & $39.5 \pm 1.16^{\mathrm{b}}$ & $43.0 \pm 1.37^{\mathrm{a}}$ \\
\hline $\mathrm{BL}(\mathrm{cm})$ & $12.8 \pm 0.08^{\mathrm{b}}$ & $13.0 \pm 0.05^{\mathrm{b}}$ & $13.3 \pm 0.17^{\mathrm{a}}$ \\
\hline $\mathrm{RIL}^{2}(\%)$ & $178 \pm 2.80^{\mathrm{a}}$ & $172 \pm 1.50^{\mathrm{ab}}$ & $169 \pm 0.13^{\mathrm{b}}$ \\
\hline $\mathrm{CF}^{3}\left(\mathrm{~g} / \mathrm{cm}^{3}\right)$ & $1.89 \pm 0.05$ & $1.82 \pm 0.01$ & $1.83 \pm 0.02$ \\
$\mathrm{SR}^{4}(\%)$ & $94.5 \pm 4.81$ & $97.2 \pm 4.81$ & $100 \pm 0.00$ \\
$\mathrm{VSI}^{5}(\%)$ & $14.7 \pm 0.54^{\mathrm{a}}$ & $14.1 \pm 0.27^{\mathrm{ab}}$ & $13.7 \pm 0.19^{\mathrm{b}}$ \\
\hline $\mathrm{KI}^{6}(\%)$ & $0.32 \pm 0.01$ & $0.31 \pm 0.01$ & $0.33 \pm 0.01$ \\
\hline $\mathrm{SI}^{7}(\%)$ & $0.13 \pm 0.05$ & $0.10 \pm 0.01$ & $0.09 \pm 0.00$ \\
\hline $\mathrm{HSI}^{8}(\%)$ & $2.95 \pm 0.03^{\mathrm{a}}$ & $3.09 \pm 0.13^{\mathrm{a}}$ & $2.62 \pm 0.11^{\mathrm{b}}$
\end{tabular}

Abbreviations: BL, body length; CF, condition factor; FBW, final body weight;

$\mathrm{HSI}$, hepatopancreas index; IBW, initial body weight; KI, kidney index; RIL, relative intestine length; SI, spleen index; SR, survival rate; VSI, viscerosomatic index.

${ }^{1}$ Values are expressed as mean \pm standard deviation (SD), $\mathrm{n}=3$ (randomly picked 10 fish from each tank, and the average of each tank is calculated, three replicates per treatment). Labeled means in a row without a common letter are significantly different, $P[0.05$ [1-factor analysis of variance (ANOVA) followed by Duncan's test].

${ }^{2}$ Relative intestine length $\triangle \mathrm{RIL}, \% \bigotimes=$ intestine length $(\mathrm{cm}) \times 100 /$ body length $(\mathrm{cm})$

${ }^{3}$ Condition factor $\left(\mathrm{CF}, \mathrm{g} / \mathrm{cm}^{3}\right)=$ body weight $(\mathrm{g}) \times 100 /$ body length $\left(\mathrm{cm}^{3}\right)$

${ }^{4}$ Survival rate $(S R, \%)=$ final number of fish $\times 100 /$ initial number of fish

${ }^{5}$ Viscera index $(\mathrm{VSI}, \%)=$ viscera weight $(\mathrm{g}) \times 100 /$ body weight $(\mathrm{g})$

${ }^{6}$ Kidney index $(\mathrm{KI}, \%)=$ kidney weight $(\mathrm{g}) \times 100 /$ body weight $(\mathrm{g})$

${ }^{7}$ Spleen index $(\mathrm{SI}, \%)=$ spleen weight $(\mathrm{g}) \times 100 /$ body weight $(\mathrm{g})$

${ }^{8}$ Hepatopancreas index $(\mathrm{HSI}, \%)=$ hepatopancreas weight $(\mathrm{g}) \times 100 /$ body weight $(\mathrm{g})$ 
Table 5. Effect of dietary DHA on serum biochemical parameters of grass carp ${ }^{1}$.

\begin{tabular}{llll} 
Index & Group & & \\
\hline & Control & $0.5 \% \mathrm{DHA}$ & $1 \% \mathrm{DHA}$ \\
\hline $\mathrm{TP}\left(\mathrm{g} \mathrm{L}^{-1}\right)$ & $24.32 \pm 2.86$ & $23.5 \pm 3.59$ & $20.6 \pm 2.44$ \\
\hline $\mathrm{ALB}\left(\mathrm{g} \mathrm{L}^{-1}\right)$ & $11.14 \pm 1.32^{\mathrm{a}}$ & $10.78 \pm 1.70^{\mathrm{ab}}$ & $9.23 \pm 0.89^{\mathrm{b}}$ \\
\hline $\mathrm{GLO}\left(\mathrm{g} \mathrm{L}^{-1}\right)$ & $13.18 \pm 1.59$ & $12.72 \pm 1.92$ & $11.36 \pm 1.57$ \\
\hline $\mathrm{A} / \mathrm{G}$ & $0.85 \pm 0.04$ & $0.85 \pm 0.03$ & $0.82 \pm 0.05$ \\
\hline $\mathrm{GLU}\left(\mathrm{mmol} \mathrm{L}^{-1}\right)$ & $5.90 \pm 1.17$ & $5.51 \pm 1.46$ & $5.04 \pm 0.98$ \\
\hline $\mathrm{HDL}-\mathrm{c}\left(\mathrm{mmol} \mathrm{L}^{-1}\right)$ & $0.73 \pm 0.10^{\mathrm{a}}$ & $0.82 \pm 0.10^{\mathrm{a}}$ & $0.61 \pm 0.04^{\mathrm{b}}$ \\
\hline $\mathrm{LDL}-\mathrm{c}\left(\mathrm{mmol} \mathrm{L}^{-1}\right)$ & $1.43 \pm 0.26^{\mathrm{b}}$ & $1.89 \pm 0.42^{\mathrm{a}}$ & $1.01 \pm 0.14^{\mathrm{c}}$
\end{tabular}

${ }^{1}$ Values are expressed as mean \pm standard deviation (SD), $\mathrm{n}=6$ fish ( 2 fish/tank). Labeled means in a row without a common letter are significantly different, $P[0.05[1$-factor analysis of variance (ANOVA) followed by Duncan's test].

Abbreviations: ALT, alanine aminotransferase; AST, aspartate aminotransferase;

A/G, albumin/ globulin; ALB, albumin; GLO, globulin;

HDL-c, high-density lipoprotein cholesterol; LDL-c, low-density lipoprotein cholesterol; TP, total protein.

Table 6. Effect of dietary DHA on the fatty acid composition of the liver in grass carp ${ }^{1}$ (\% total fatty acid). 
Components Group

\begin{tabular}{|c|c|c|c|}
\hline & Control & $0.5 \% \mathrm{DHA}$ & $1 \% \mathrm{DHA}$ \\
\hline $14: 0$ & $1.98 \pm 0.23^{a}$ & $1.67 \pm 0.18^{b}$ & $1.77 \pm 0.05^{a b}$ \\
\hline $16: 0$ & $24.4 \pm 2.07^{a}$ & $21.6 \pm 0.64^{b}$ & $17.2 \pm 1.64^{c}$ \\
\hline $18: 0$ & $6.28 \pm 0.78^{a}$ & $6.62 \pm 1.16^{a}$ & $3.95 \pm 0.44^{b}$ \\
\hline SFA & $31.6 \pm 0.89^{a}$ & $29.9 \pm 1.16^{a}$ & $22.9 \pm 2.04^{b}$ \\
\hline $16: 1 n-7$ & $10.0 \pm 1.33$ & $9.34 \pm 0.90$ & $11.2 \pm 0.85$ \\
\hline $18: 1 n-9 c$ & $47.5 \pm 1.62$ & $48.7 \pm 3.58$ & $48.5 \pm 2.06$ \\
\hline MUFA & $57.5 \pm 2.02$ & $58.0 \pm 4.20$ & $59.7 \pm 2.70$ \\
\hline $18: 2 n-6$ & $3.08 \pm 0.78$ & $3.45 \pm 1.45$ & $4.13 \pm 1.08$ \\
\hline $18: 3 n-6$ & $0.15 \pm 0.04$ & $0.15 \pm 0.06$ & $0.17 \pm 0.03$ \\
\hline $20: 4 n-6$ & $1.34 \pm 0.46$ & $0.95 \pm 0.37$ & $1.25 \pm 0.08$ \\
\hline $22: 4 n-6$ & $0.43 \pm 0.07^{b}$ & $0.51 \pm 0.10^{b}$ & $0.90 \pm 0.22^{a}$ \\
\hline n-6PUFA & $5.62 \pm 0.93$ & $5.67 \pm 1.74$ & $7.10 \pm 1.40$ \\
\hline $18: 3 n-3$ & $3.07 \pm 0.39$ & $3.25 \pm 1.34$ & $4.44 \pm 0.66$ \\
\hline $20: 5 n-3$ & $0.50 \pm 0.18^{a}$ & $0.26 \pm 0.15^{b}$ & $0.24 \pm 0.04^{b}$ \\
\hline $22: 6 n-3$ & $1.60 \pm 0.42^{c}$ & $2.94 \pm 1.02^{b}$ & $5.26 \pm 0.74^{a}$ \\
\hline n-3HUFA & $2.10 \pm 0.58^{b}$ & $3.20 \pm 1.34^{b}$ & $5.50 \pm 0.74^{a}$ \\
\hline n-3PUFA & $5.17 \pm 0.52^{b}$ & $6.45 \pm 2.34^{b}$ & $9.93 \pm 1.16^{a}$ \\
\hline PUFA & $10.8 \pm 1.33^{b}$ & $12.1 \pm 4.03^{b}$ & $17.0 \pm 2.17^{a}$ \\
\hline n-3/n-6PUFA & $0.92 \pm 0.56^{b}$ & $1.13 \pm 0.14^{b}$ & $1.43 \pm 0.30^{a}$ \\
\hline
\end{tabular}

${ }^{1}$ Values are expressed as mean \pm standard deviation (SD), $\mathrm{n}=6$ fish ( 2 fish/tank). Labeled means in a row without a common letter are significantly different, $P[0.05$ [1-factor analysis of variance (ANOVA) followed by Duncan's test].

Abbreviations: MUFA, monounsaturated fatty acid; n-3 PUFA, n-3 polyunsaturated fatty acids; n-3PUFA, n3 polyunsaturated fatty acids; n-3PUFA/n-6PUFA, the ratio of n-3 polyunsaturated fatty acids and n- 6 polyunsaturated fatty acids; n-6 PUFA, n-6 polyunsaturated fatty acids; SFA, saturated fatty acids. 


\section{Figures}

A
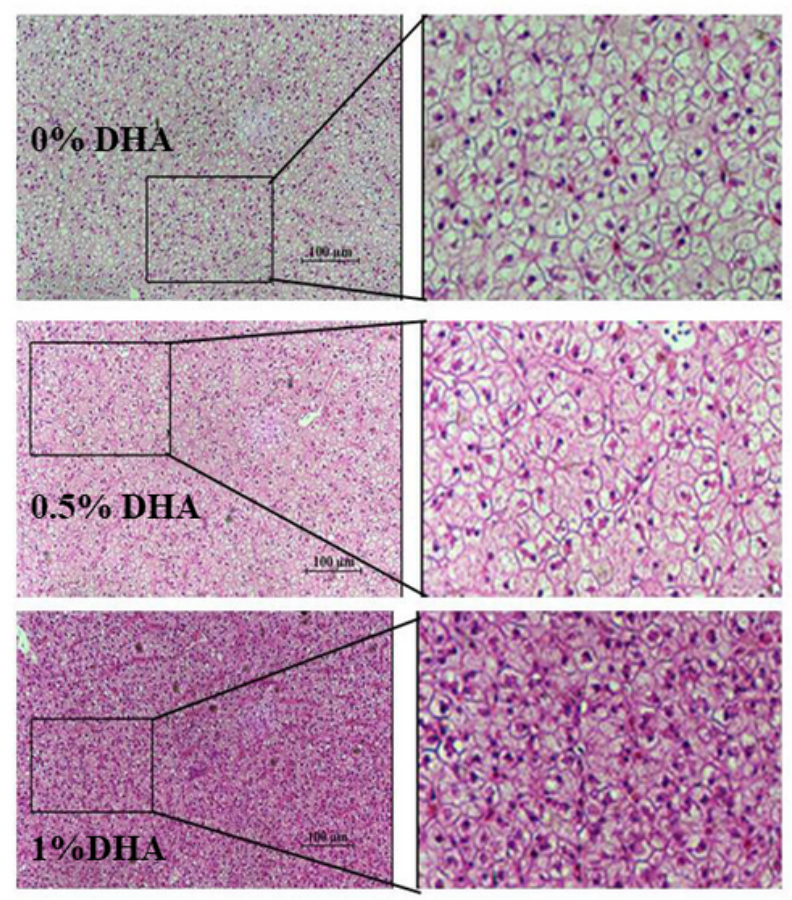
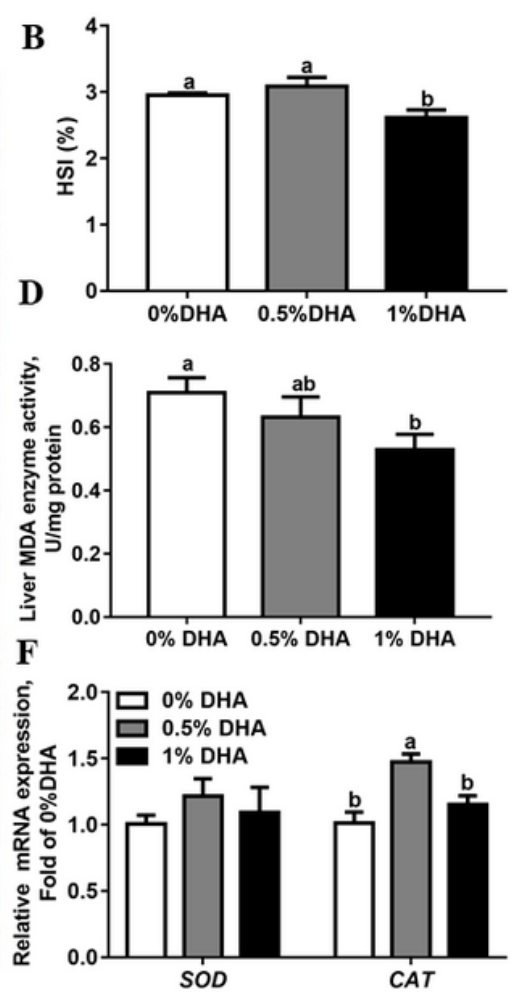
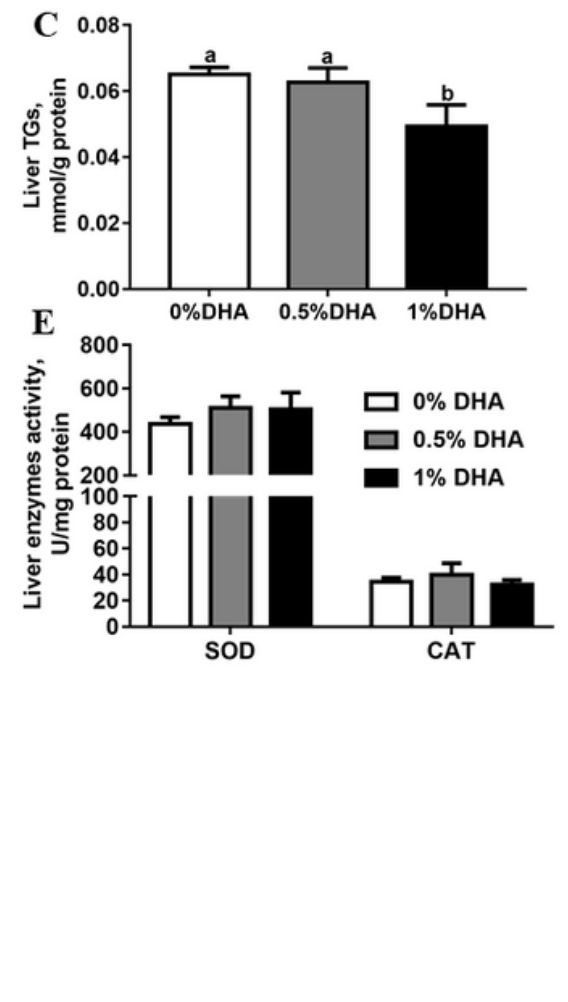

\section{Figure 1}

DHA attenuates lipid accumulation and improves liver antioxidant capacity (Experiment 1). (A) The representative hematoxylin \& eosin (H\&E) staining of liver sections; (B) hepatosomatic index; (C) TG liver levels; (D-E) the liver contents of MDA, SOD and CAT; $(F)$ the mRNA expression levels of SOD and CAT. Values are expressed as mean \pm standard deviation (SD), $\mathrm{n}=6$ fish (2 fish/tank). Labeled means without a common letter are significantly different, Pख0.05 [1-factor analysis of variance (ANOVA) followed by Duncan's test]. CAT, catalase; MDA, maleic dialdehyde; SOD, superoxide dismutase; TG, triglyceride. 

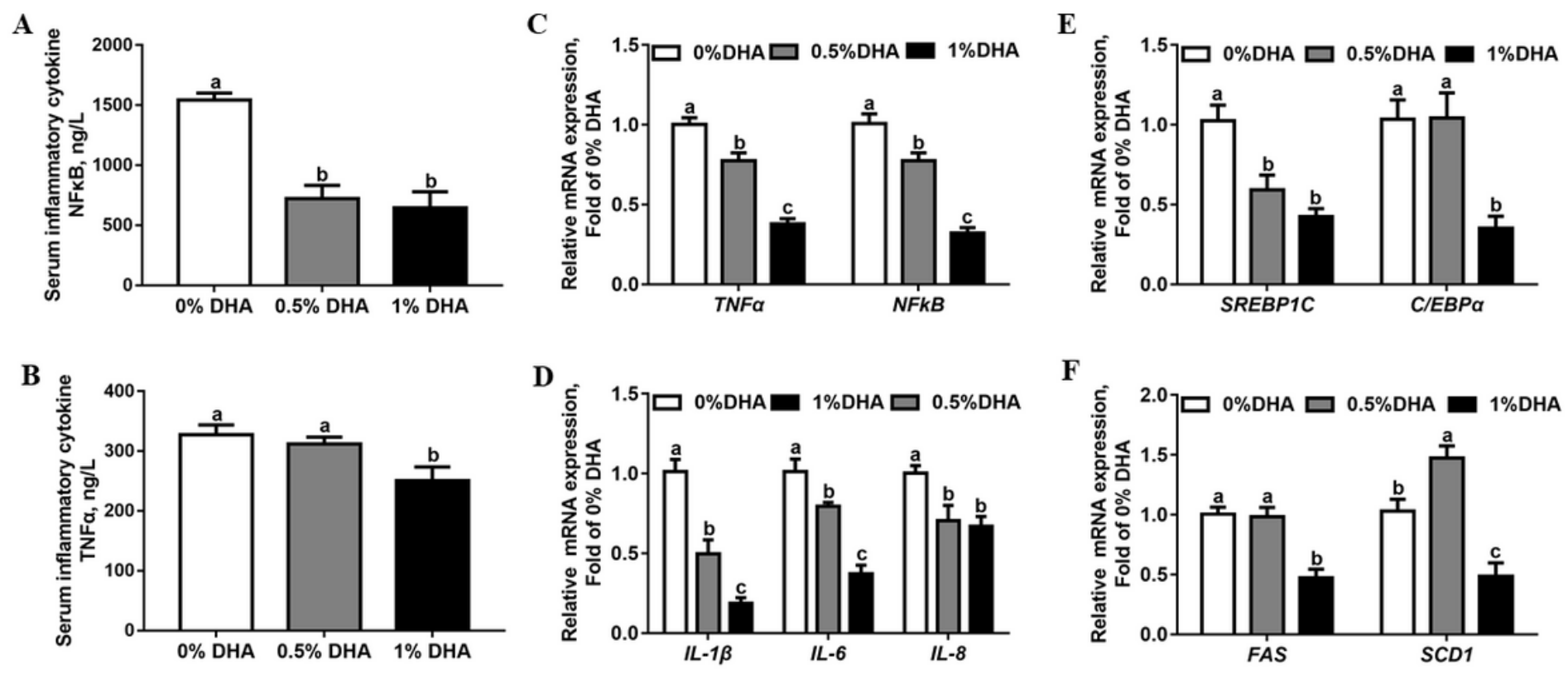

\section{Figure 2}

DHA inhibits the expression of hepatic lipid synthesis and inflammation-related genes (Experiment 1). (AB) Serum levels of NFKB and TNFa; (C-D) the mRNA expression of TNFa, NFKB, IL-1 3, IL- 6 and IL-8 in the liver; (E-F) the mRNA expression of SREBP1C, C/EBPa, FAS and SCD1 in the liver. Values are expressed as mean \pm standard deviation (SD), $\mathrm{n}=6$ fish (2 fish/tank). Labeled means without a common letter are significantly different, $\mathrm{P} \otimes 0.05$ [1-factor analysis of variance (ANOVA) followed by Duncan's test]. 
A
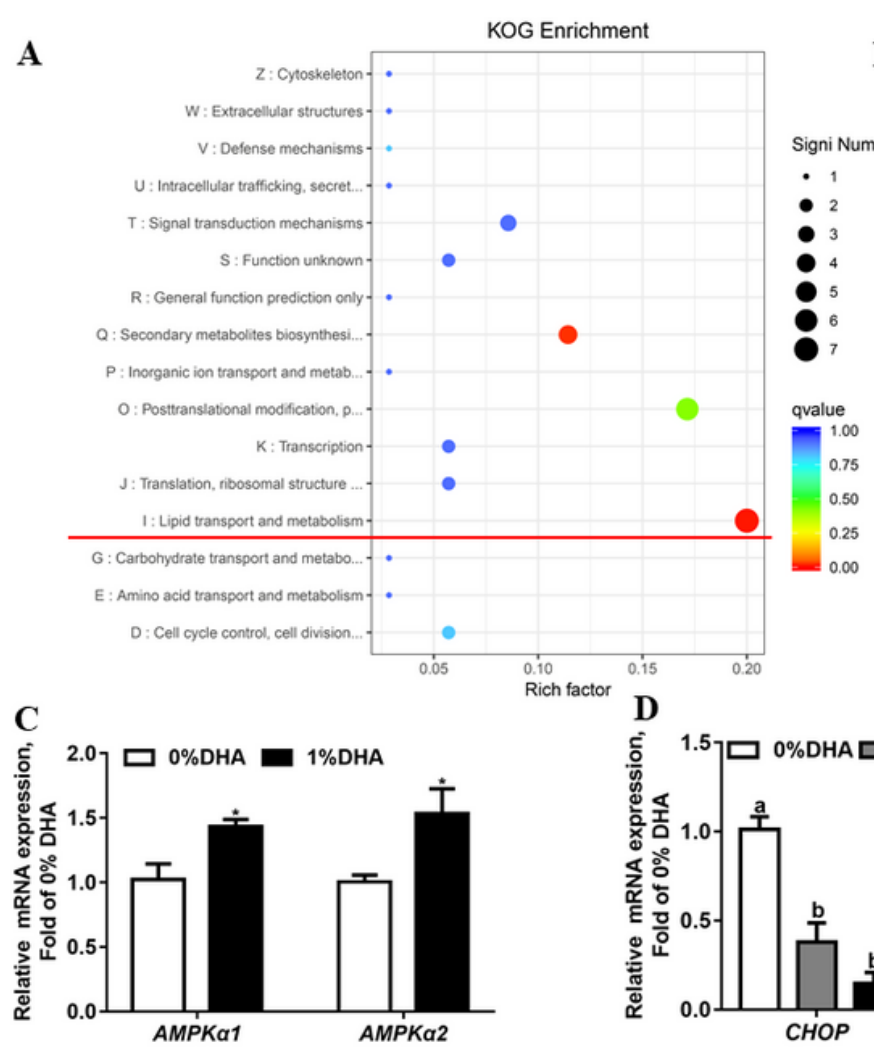

B
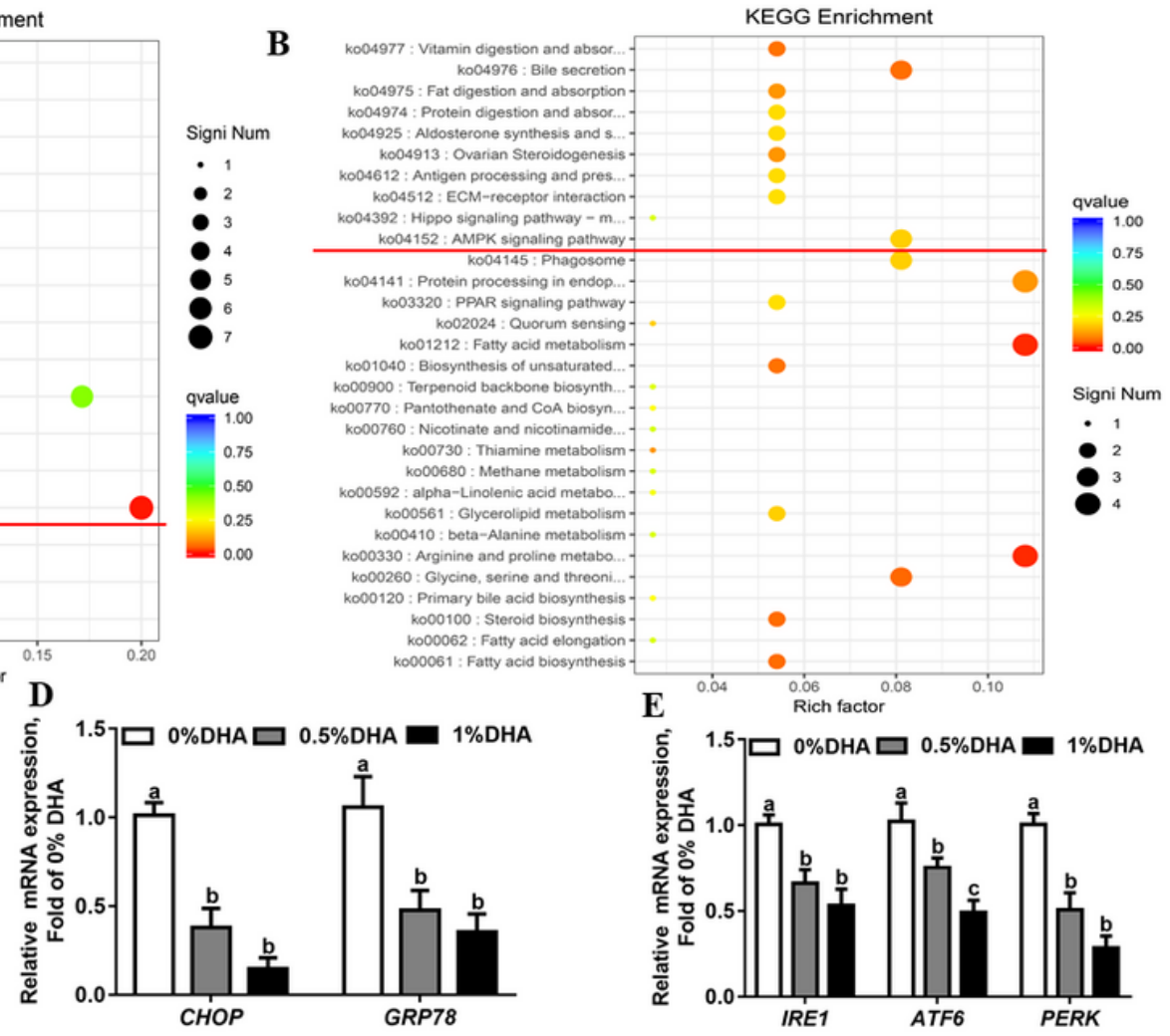

Figure 3

DHA activates AMPK and inhibits ER stress signaling pathways to influence hepatic lipid metabolism (Experiment 1). (A) The up-regulated EuKaryotic Orthologous Group (KOG) biological pathways in the 1\% DHA group when compared with the control group $(n=3)$; $(B)$ the up-regulated Kyoto Encyclopedia of Genes and Genomes (KEGG) signaling pathways in 1\% DHA group relative to the control group $(n=3)$; $(C)$ the AMPK mRNA expression ( $n=6$ fish, 2 fish/tank); (D-E) the mRNA expression of CHOP, GRP78, IRE1, ATF6 and PERK ( $n=6$ fish, 2 fish/tank). Values are expressed as mean \pm standard deviation (SD). Labeled means without a common letter are significantly different, P®0.05 [1-factor analysis of variance (ANOVA) followed by Duncan's test]. *Different from control, Pख0.05 (Student t test). 

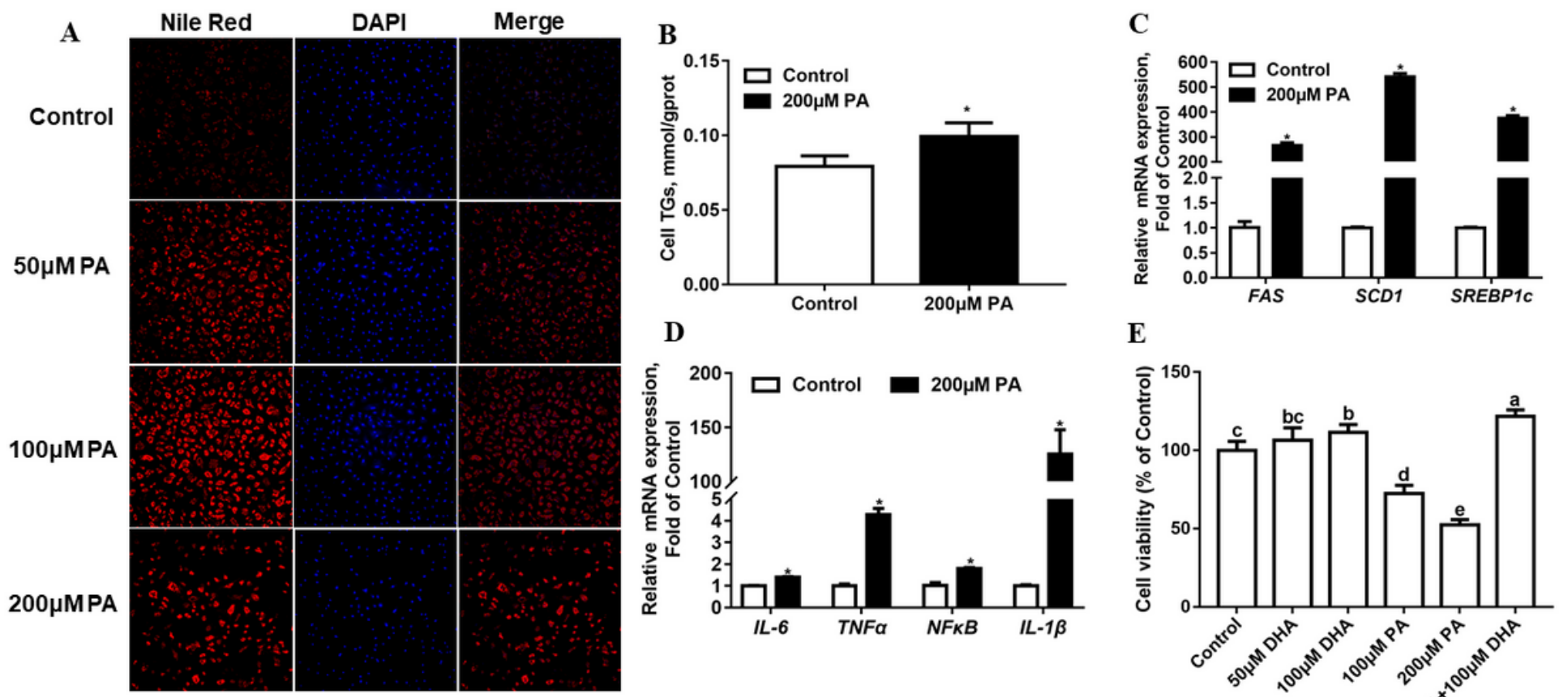

Figure 4

DHA affects cell viability and PA-induced lipid accumulation in hepatocytes (Experiment 2). (A) A representative of cell Nile red staining; (B) cell TG; (C) the mRNA expression of FAS, SCD1 and SREBP1C; (D) the mRNA expression of IL-6, TNFa, NFKB and IL-1 3 ; (E) cell viability. Values are expressed as mean \pm standard deviation (SD), $n \geq 3$ (cell TG, $n=4$; the mRNA expression, $n=3$; cell viability, $n=6$ ). Labeled means without a common are significantly different, $P \otimes 0.05$ [1-factor analysis of variance (ANOVA) followed by Duncan's test]. $*$ Different from control, $\mathrm{P} \otimes 0.05$ (Student $t$ test). 


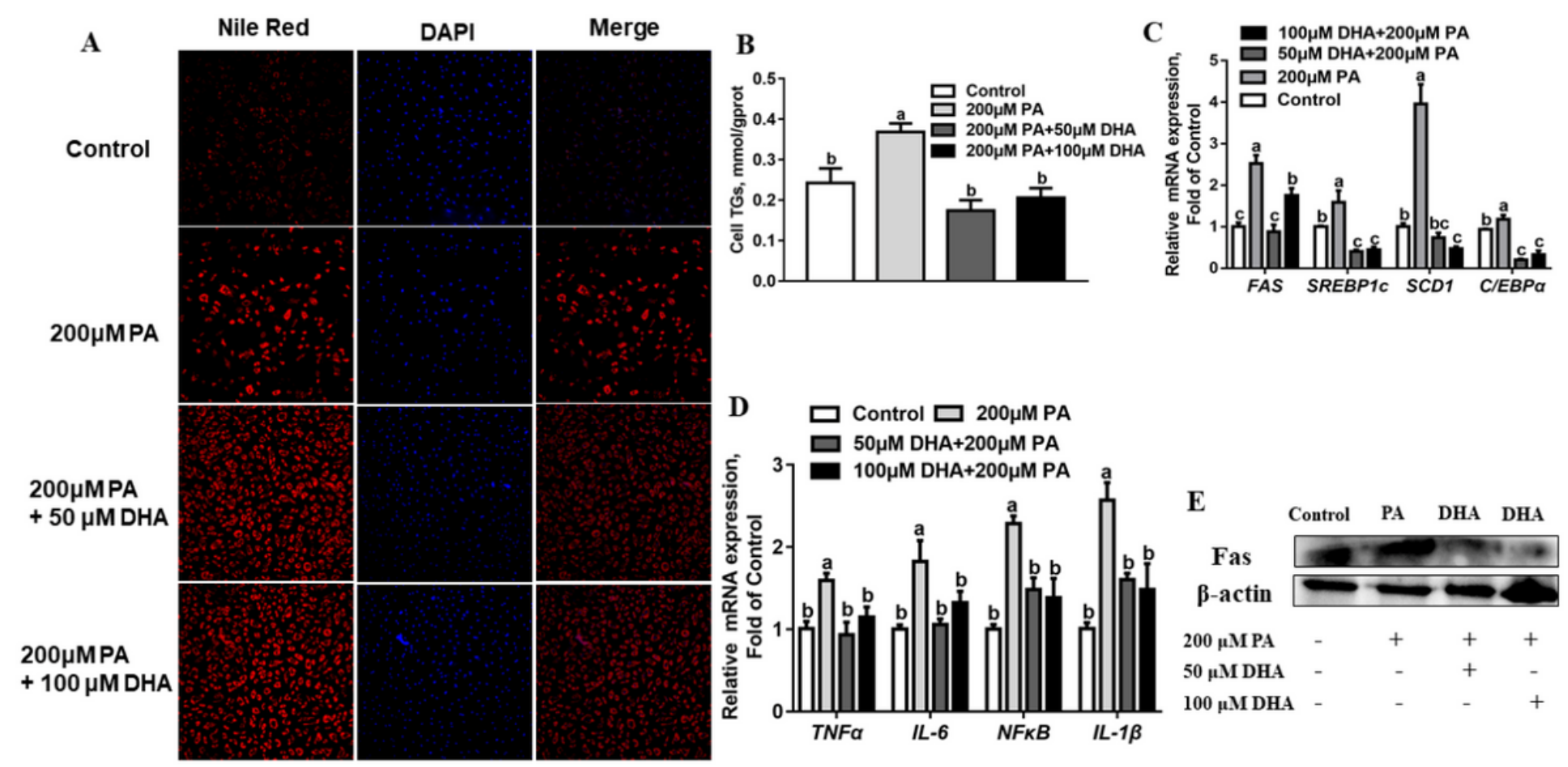

Figure 5

DHA ameliorates PA-induced inflammation and lipid synthesis in hepatocytes (Experiment 2). (A) A representative of cell Nile red staining; (B) cell TG; (C) the mRNA expression of FAS, SREBP1c, SCD1 and $\mathrm{C} / \mathrm{EBPa}$; (D) the mRNA expression of TNFa, IL-6, NFKB and IL-1 $\beta$; (E) western blot analysis on FAS expression. Values are expressed as mean \pm standard deviation (SD), $n \geq 3$ (cell TG, $n=4$; the mRNA expression, $\mathrm{n}=3$ ). Labeled means without a common letter are significantly different, $\mathrm{P} \otimes 0.05$ [1-factor analysis of variance (ANOVA) followed by Duncan's test]. 

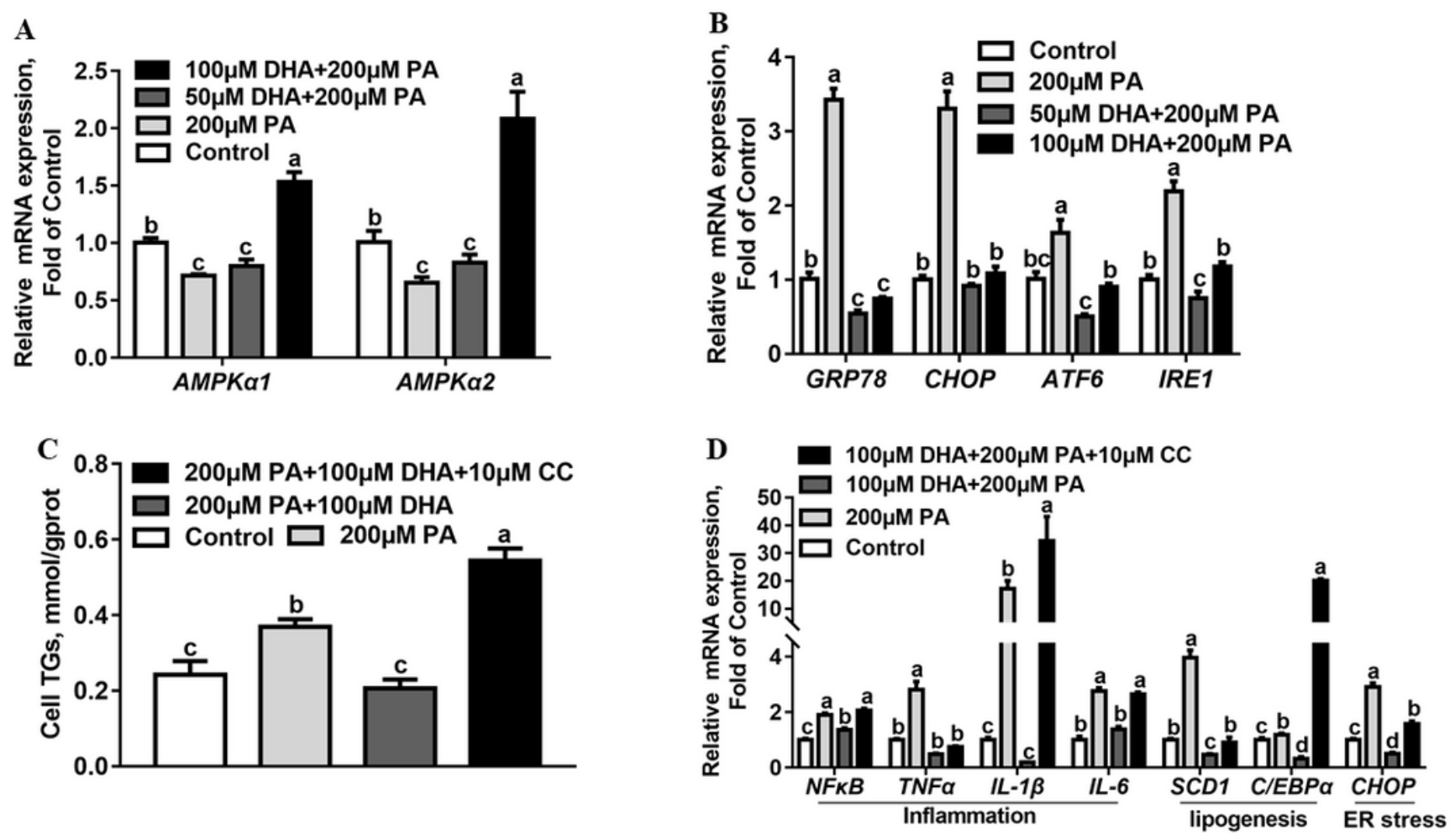

Figure 6

DHA ameliorates hepatic lipid synthesis and inflammation via the AMPK signaling pathway in hepatocytes (Experiment 2). (A) The AMPKa1 and AMPKa2 mRNA expression; (B) the mRNA expression of different ER stress genes, including GRP78, CHOP, ATF6 and IRE1; (C) cell TG; (D) the mRNA expression of genes involved in inflammation, lipogenesis and ER stress. Values are expressed as mean \pm standard deviation (SD), $n \geq 3$ (cell TG, $n=4$; the mRNA expression, $n=3$ ). Labeled means without a common letter are significantly different, $\mathrm{P} \otimes 0.05$ [1-factor analysis of variance (ANOVA) followed by Duncan's test]. 


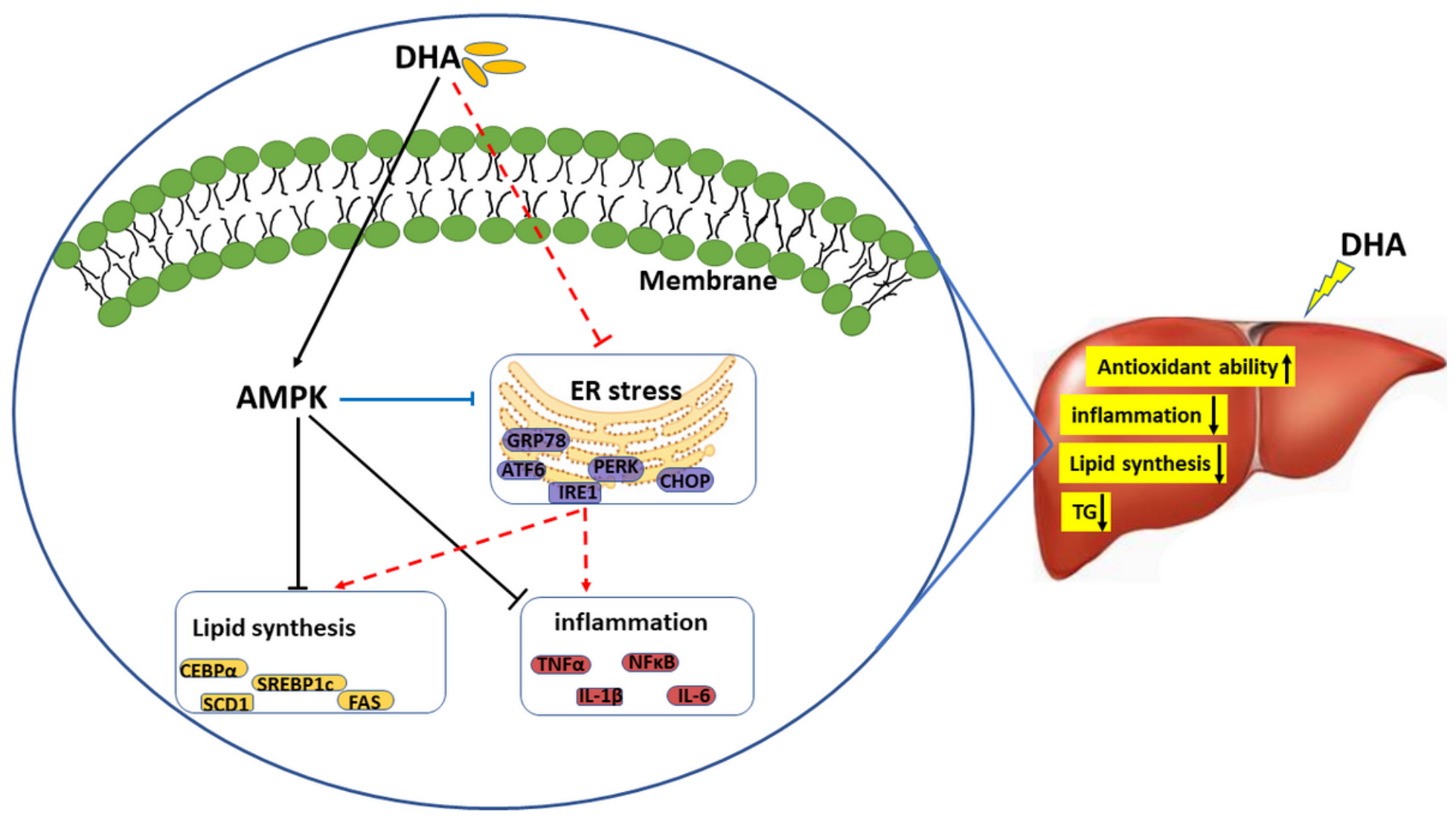

Figure 7

DHA ameliorates palmitic acid-induced lipid accumulation in grass carp hepatocytes. Therefore, the underlying mechanism could be associated with inhibiting ER stress, improving antioxidant ability, relieving hepatic inflammation and inhibiting hepatic lipogenesis in an AMPK-dependent manner. 